Article

\title{
Ductility Estimation of Concrete Beams Longitudinally Rein- forced with Hybrid FRP-Steel Bars
}

\author{
Rendy Thamrin * Zaidir Zaidir and Devitasari Iwanda
}

Department of Civil Engineering, Faculty of Engineering, Andalas University, Padang 25163, West Sumatera, Indonesia; zaidir2000@yahoo.com (Z.Z.); devitasariiwanda@gmail.com (D.I.)

* Correspondence: rendythamrin@eng.unand.ac.id

\begin{abstract}
An experimental study was carried out to evaluate the ductility of reinforced concrete beams longitudinally reinforced with hybrid FRP-Steel bars. The specimens were fourteen reinforced concrete beams with and without hybrid reinforcement. The test variables were bars position, the ratio of longitudinal reinforcement, and the type of FRP bars. The beams were loaded up to failure using a four-point bending test. The performance of the tested beams was observed using the load-deflection curve obtained from the test. Numerical analysis using the fiber element model was used to examine the growth of neutral axis depth due to the effect of test variables. The neutral axis curves were then used to further estimate the neutral axis angle and neutral axis displacement index. The test results show that the position of the reinforcement greatly influences the flexural behavior of the beam with hybrid reinforcement. It was observed from the test that the flexural capacity of beams with hybrid reinforcement is $4 \%$ to $50 \%$ higher than that of the beams with conventional steel bars depending on bars position and the ratio of longitudinal reinforcement. The ductility decreases as the hybrid reinforcement ratio (Af/As) increases. This study also showed that a numerical model developed can predict the flexural behavior of beams with hybrid reinforcement with reasonable accuracy.
\end{abstract}

Keywords: hybrid FRP-steel reinforcement, ductility, hybrid reinforcement ratio, fiber element, neutral axis

\section{Introduction}

The main idea for using hybrid FRP-steel reinforcement in reinforced concrete structures is to anticipate the weaknesses of FRP material which is brittle, has low elastic modulus [1], and is not resistant to fire [2]. Other researchers have carried out studies on the flexural performance of reinforced concrete beams with hybrid FRP-steel reinforcement over the last 20 years [1,2]. In recent times, the number of these studies has increased rapidly. Some research results related to these studies are described as follows.

It has been shown that the use of steel reinforcement in combination with GFRP reinforcement increases the flexural capacity and ductility of reinforced concrete beams due to the presence of steel bars [3]. Another study demonstrated that the ductility of beams with FRP reinforcement could be improved by either increasing the ratio of reinforcement or adding conventional steel bars [4]. The arrangement of the steel bars plays an essential role in the stiffness and crack width of reinforced concrete with hybrid FRP-steel reinforcement [5]. It has also been reported that the deflection and crack width of beams with both hybrid BFRP and steel reinforcement were smaller than those beams reinforced with only BFRP bars [6].

The experimental tests using two types of FRP indicated that beams with hybrid GFRP-steel reinforcement demonstrated significantly reduced stiffness after the first cracking and yielding of steel reinforcement compared to hybrid beams with CFRP-steel reinforcement [7]. Results of a numerical study using cross-section analysis of reinforced 
concrete beams were also presented in this report. The analytical model showed promising results in predicting the moment capacity of reinforced concrete beams with hybrid NSM FRP bars/strips reinforcement.

The study conducted by Refai et al. [8] concluded that using hybrid reinforcement (steel and GFRP) improved the flexural behavior of the beam in terms of deformability, cracking, stiffness, and beam capacity compared to beams that only used GFRP reinforcement. In addition, to ensure adequate beam deformation, the report recommends that beams with hybrid reinforcement design consider the yield of steel before concrete crushing or FRP fracture.

Qin et al. [9] conducted a numerical analysis using 15 finite element models. Six of them closely modeled experimental results for the flexural behavior of beams with hybrid FRP-steel reinforcement. It was concluded from this report that the finite element model used can be applied to predict the flexural behavior of hybrid FRP-steel beams accurately. This study points out that in beams with over-reinforced reinforcement, the hybrid reinforcement ratio, Af/As, must be designed in the range of 1 to 2.5 to ensure that the beam still has strength with sufficient ductility and stiffness after exceeding the elastic phase.

In another report, Bui et al. [10] also found differences in behavior between beams with FRP-steel hybrid beams and conventional reinforced concrete beams. This report states that for beams with hybrid reinforcement, FRP reinforcement is responsible for ultimate capacity, while steel reinforcement is responsible for the ductility of the beam. Therefore, the ductility of the beam with a hybrid reinforcement can be increased if the $A_{f} / A_{s}$ reinforcement ratio is small.

Araba and Ashour [11] demonstrated that the moment capacity of beams with hybrid reinforcement is more influenced by the ratio of hybrid reinforcement than the axial stiffness ratio $\left(A_{s} E_{s} / A_{f} E_{f}\right)$. They also reported that the addition of axial stiffness is not proportional to the increase in moment capacity.

Sun et al. [12] examined the effect of reinforcement arrangement in beams with hybrid reinforcement experimentally. They discovered that the deflection of the beam with a distributed reinforcement arrangement was smaller than if the reinforcement was bundled. This study also showed that beams with hybrid reinforcement had sufficient ductility.

The report presented by Kartal et al. [13] provides information about the zoning of the load-deflection curve. The load-deflection curve of beams with hybrid reinforcement can be divided into three parts, namely the zone before and after flexural cracking, then the zone after the tensile reinforcement has yielded. This report also states that the deformation capacity of the beam with hybrid reinforcement increases with the increase in the amount of FRP reinforcement in the tension zone.

Hence, current research demonstrates conclusively that beams with hybrid reinforcement have increased stiffness, flexural capacity, and ductility compared to beams reinforced with pure FRP. The results of previous studies also show that as the hybrid reinforcement ratio $\left(A_{f} / A_{s}\right)$ increases, the determination of the ductility will be more complex because the yield position of the steel is not clear. Although several previous researchers have investigated many attributes of hybrid reinforced beam flexural behavior, some features of the performance of these beams are still unclear. In particular, the effects of the hybrid reinforcement ratio $\left(A_{f} / A_{s}\right)$ and the arrangement of hybrid reinforcement on the flexural performance of reinforced concrete beams with hybrid FRP-steel bars have not been thoroughly investigated.

Therefore, the main objective of this experimental study was to investigate the effects of the reinforcement ratio and the arrangement of hybrid reinforcement on the flexural performance and ductility of reinforced concrete beams with hybrid FRP-steel bars. Neutral axis angle and neutral axis displacement index are also introduced to evaluate the ductility of beams with hybrid reinforcement. The curves of neutral axis growth obtained with the help of a computer program were used to determine the neutral axis angle and 
neutral axis displacement index. In addition, this study also adds data regarding the effects of using hybrid FRP-steel as internal reinforcement.

Fourteen reinforced concrete beams consisting of six control beams and eight with hybrid reinforcement were tested experimentally. The effect of the hybrid reinforcement ratio was examined by varying the amount of FRP and steel reinforcement in the tensile region of the beam. Meanwhile, the influence of the reinforcement position was investigated using two types of bar arrangement. The data in this study were combined with the data obtained from parametric analysis and data obtained from the literature. Numerical analysis to obtain flexural capacity, strain behavior, and neutral axis growth due to the effects of the test variables was also performed using the fiber element model.

\section{Experimental Study}

This study tested fourteen simply supported concrete beams; with six control beams and eight beams with hybrid steel-FRP reinforcement. The beams were monotonically loaded until failure with a two-point load using a hydraulic jack. Loading position and dimension of the beam are shown in Figure 1(a). The clear span was $2000 \mathrm{~mm}$ for all tested beams, the shear span length was $800 \mathrm{~mm}$, and the end anchorage length beyond the support was $150 \mathrm{~mm}$. The dimensions of the beam cross-section, the configuration of the reinforcement position, and the type of reinforcement used are shown in Figures 1(b) to 1(o).
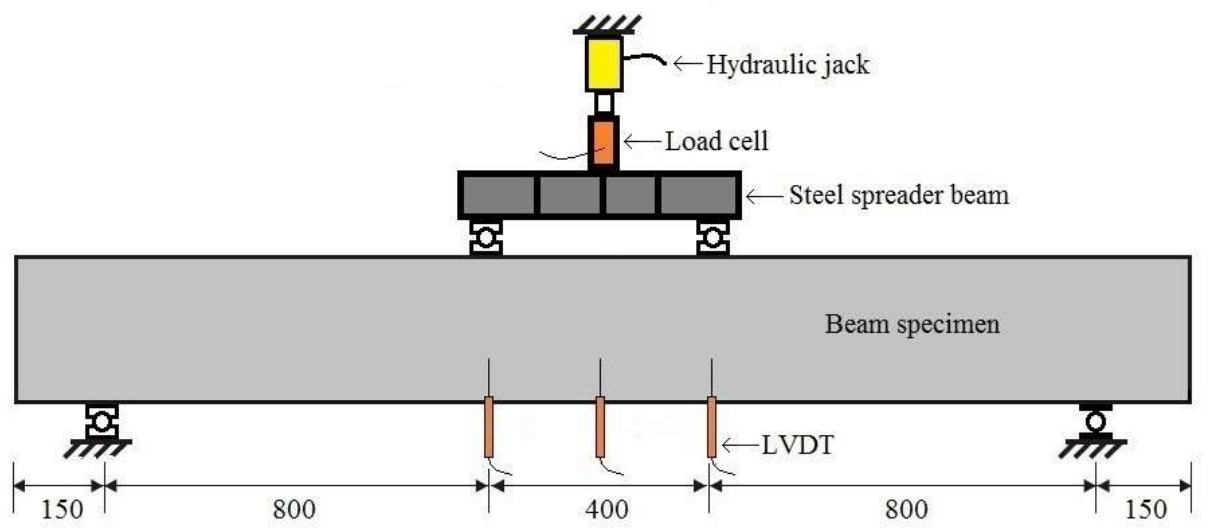

(a)

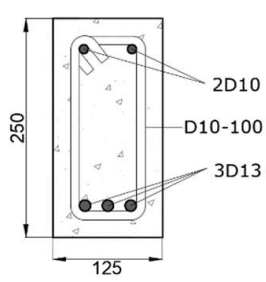

(b)

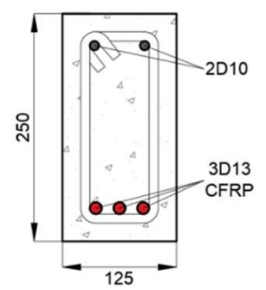

(f)

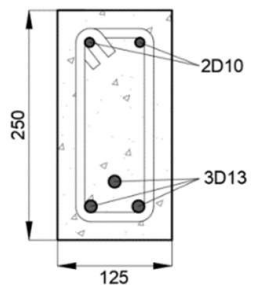

(c)

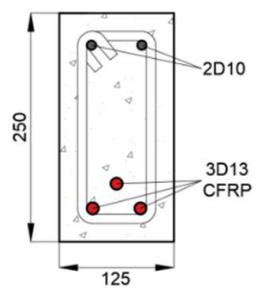

(g)

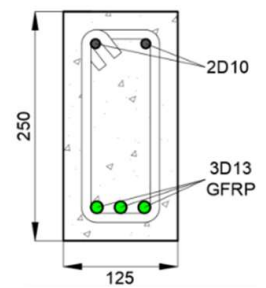

(d)

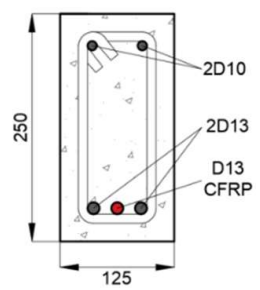

(h)

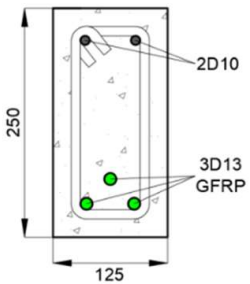

(e)

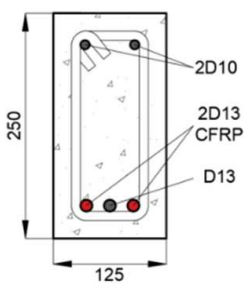

(i) 


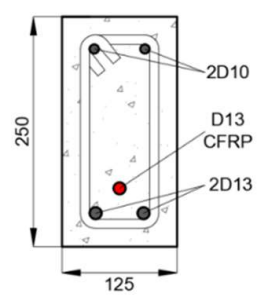

(j)

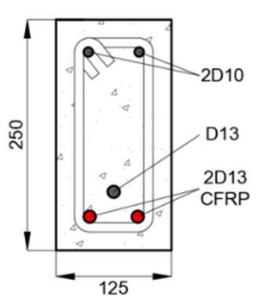

(k)

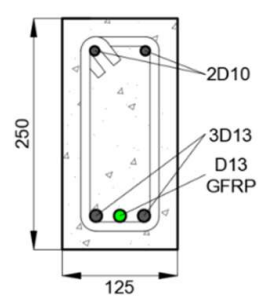

(1)

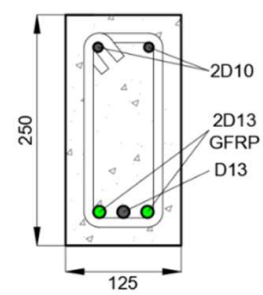

$(\mathrm{m})$

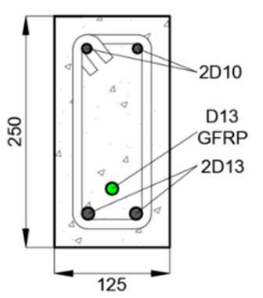

(n)

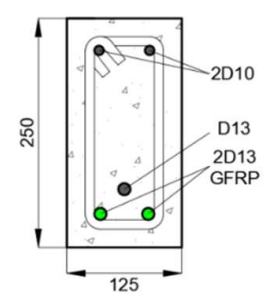

(o)

Figure 1. Schematic pictures of the tested beams and their identifications (a) beam dimension and loading position, (b) BFS-2, (c) BFS-4, (d) BFG-1, (e) BFG-2, (f) BFC-1, (g) BFC-2, (h) BHC-1, (i) BHC-2, (j) BHC-3, (k) BHC-4, (l) BHG-1, (m) BHG-2, (n) BHG-3, and (o) BHG-4.

Two types of cross-sections, as shown in Figure 1, were used. The first type (Type I) was a beam section with one layer of tensile reinforcement (Figure 1(b)), and the second type (Type II) was a beam section with two layers of tensile reinforcement (Figure 1(c)). The six control beams consisted of two beams with steel reinforcement (BFS-2 \& BFS-4), two beams with GFRP reinforcement (BFG-1 \& BFG-2), and two beams with CFRP reinforcement (BFC-1 \& BFC-2). The eight beams with FRP-steel hybrid reinforcement are distinguished by the two cross-sections and the ratio of FRP reinforcement to steel reinforcement.

Figure 2(a) shows the FRP reinforcement used in this study. Reinforcement cages before concrete casting and experimental setup and equipment used in beam tests are shown in Figure 2(b) and 2(c), respectively.

Fresh concrete was ordered from a ready-mix company and the compressive strength of the concrete at 28 days was $20 \mathrm{MPa}$. The thickness of the concrete cover is $30 \mathrm{~mm}$. The longitudinal reinforcement used consisted of steel bars with a diameter of $13 \mathrm{~mm}$ with a yield stress of $375 \mathrm{MPa}$, GFRP bars with a diameter of $13 \mathrm{~mm}$ with an ultimate tensile strength of $788 \mathrm{MPa}$, and CFRP bars with a diameter of $13 \mathrm{~mm}$ with a maximum tensile strength of $2070 \mathrm{MPa}$. The ratio of FRP reinforcement to steel reinforcement was 0.5 and 2.0, respectively. The GFRP and CFRP rods used and shown in Figure 2(a) were supplied by FYFE Co. LLC from the USA. The mechanical properties of the FRP rods used in this study were obtained from the leaflet issued by the manufacturer. Transverse reinforcement with a diameter of $10 \mathrm{~mm}$ and yield stress of $454 \mathrm{MPa}$ was used for all specimens. The properties of the materials used in this study, parametric studies, and data adopted from the literature are shown in Table 1.

Table 1. Material properties of the tested beams, specimens used in the parametric study, and data adopted from literature.

\begin{tabular}{cccccccccc}
\hline $\begin{array}{c}\text { Beam } \\
\text { Notation }\end{array}$ & $\begin{array}{c}\text { Width } \\
(\mathbf{m m})\end{array}$ & $\begin{array}{c}\text { Overall } \\
\text { depth } \\
(\mathbf{m m})\end{array}$ & $\begin{array}{c}\text { Clear Span } \\
\text { Length } \\
(\mathbf{m m})\end{array}$ & $\begin{array}{c}f_{c}{ }^{\prime} \\
(\mathbf{M P a})\end{array}$ & $\begin{array}{c}f_{f u} \\
(\mathbf{M P a})\end{array}$ & $\begin{array}{c}f_{y} \\
(\mathbf{M P a})\end{array}$ & $\begin{array}{c}d_{f} \\
(\mathbf{m m})\end{array}$ & $\begin{array}{c}d_{s} \\
(\mathbf{m m})\end{array}$ & $\begin{array}{c}E_{f} \\
(\mathbf{G P a})\end{array}$ \\
\hline BFS-2 & 125 & 250 & 2000 & 20 & - & 375 & - & 13
\end{tabular}




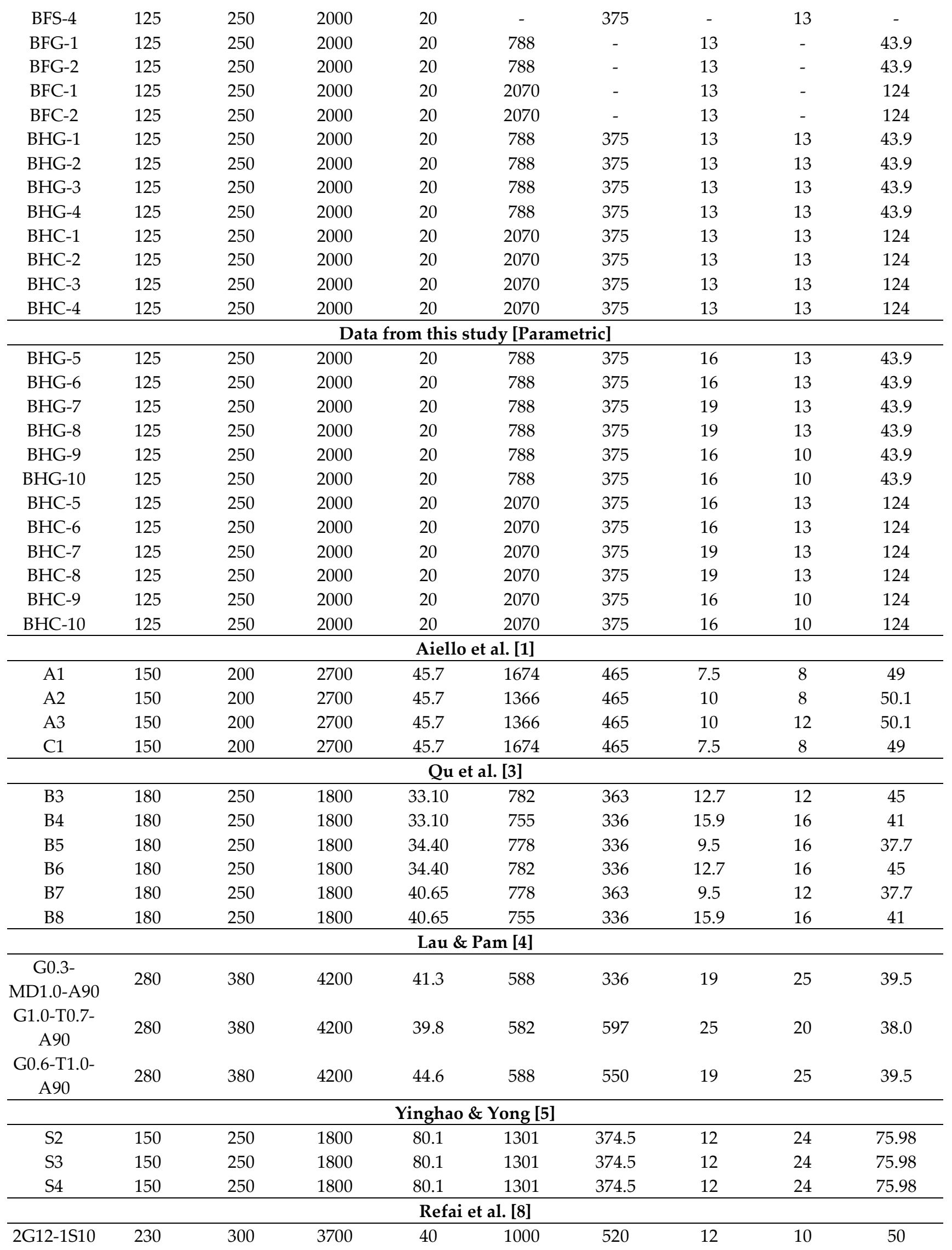




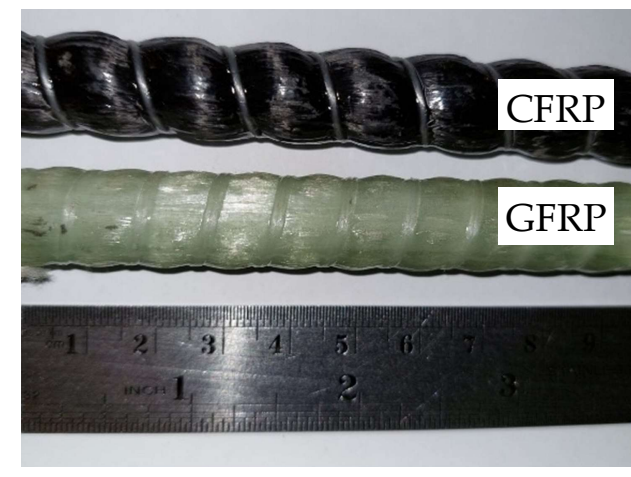

(a)

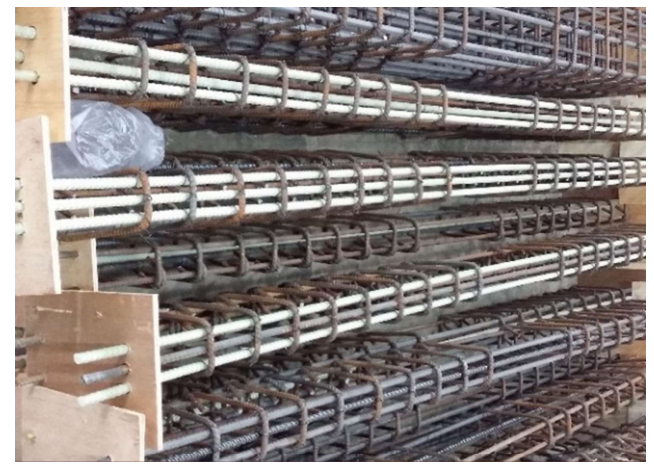

(b)

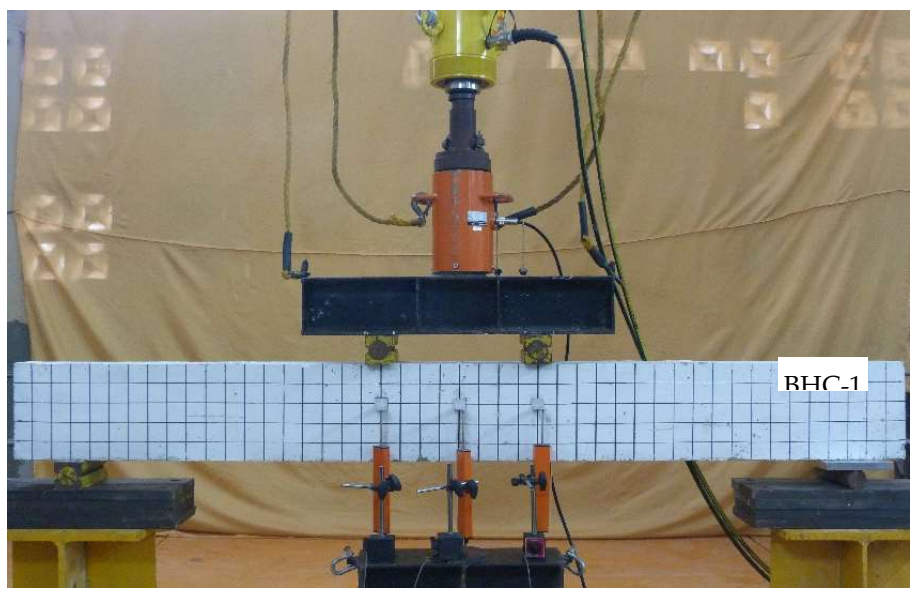

(c)

Figure 2. (a) GFRP and CFRP bars used in this study, (b) reinforcement cages before concrete casting, and (c) experimental setup and equipment used in beam test.

The load was measured using load cells in the experimental study, and the deflection was measured using linear variable displacement transducers (LVDTs). The load cell and LVDTs were connected to the data acquisition system, and the data was collected on the data storage system. The load was increased gradually until failure occurred. The test setup, load position, and LVDT placement on the test beam are shown in Figure 1. The load cell, LVDTs, and data logger used were products of Tokyo Measuring Instruments Laboratory Co., Ltd., Tokyo, Japan.

Additional data were also obtained from the literature [1, 3, 4, 5, and 8] to increase the data population with further variations in the hybrid reinforcement ratio used, ranging from 0.3 to 2.9. Two types of FRP materials (AFRP and GFRP) were represented in experimental data adopted from the literature. Two types of cross-sections based on the number of layers of tensile reinforcement are also included in this additional data.

\section{Analytical Study}


The analytical study in this research uses a fiber element model as shown in Figure 3 to obtain the theoretical moment-curvature curve of reinforced concrete sections using a nonlinear material stress-strain relationship [14]. The theoretical moment-curve curves for reinforced concrete sections under flexural loads can be derived based on the following assumptions: the cross-sections before bending remain plane after bending, and the stressstrain curves for concrete and steel are known. The moment-curvature analysis is also a method to accurately determine a reinforced concrete section's load-deformation behavior.

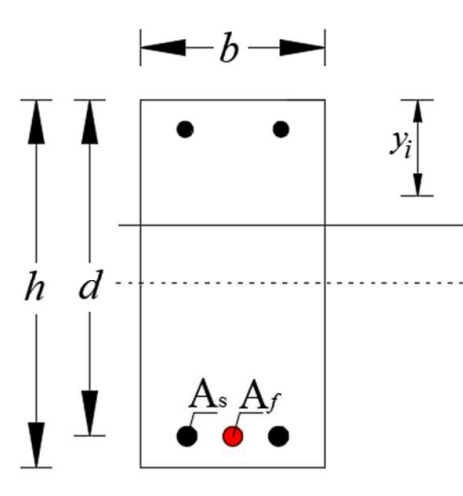

(a)

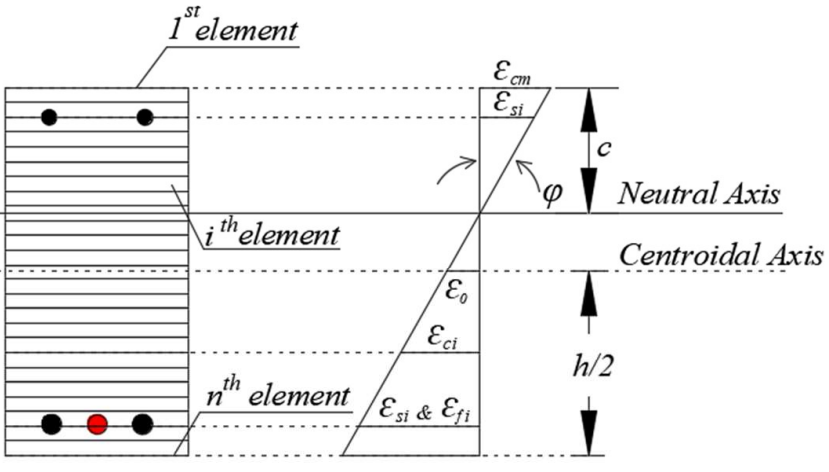

(b) (c)

Figure 3. Analytical model using the fiber element model (a) reinforced concrete crosssection, fiber element model, and (c) strain distribution.

This method begins by dividing the reinforced concrete section into layers of small elements. The reinforcement position is also located into layers of reinforcement from the top of the cross-section. Strains in each layer $\left(\varepsilon_{i}\right)$ can then be calculated using the distance of each element to the top of the cross-section $\left(y_{i}\right)$ and by assuming curvature $(\mu)$ (Equation 1).

$$
\varepsilon_{i}=\varepsilon_{o}-\left(\mu y_{i}\right)
$$

Furthermore, the force on each element $\left(F_{i}\right)$ is calculated using the stress $\left(\sigma_{i}\right)$ and the area of each element $\left(A_{i}\right)$. The stresses are obtained from the nonlinear material stressstrain relationship inputted in the previous step. Material stress-strain models used in this study are shown in Figure 4.

$$
\sigma_{i}=f\left(\varepsilon_{i}\right)
$$

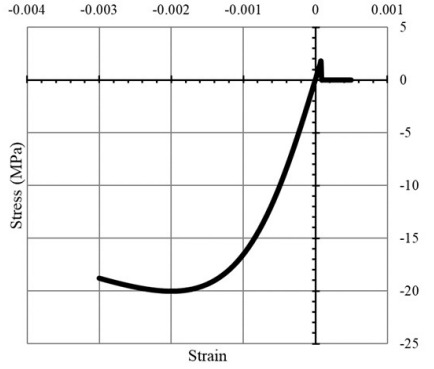

(a)

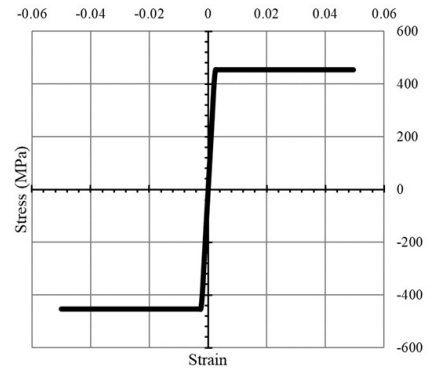

(b)

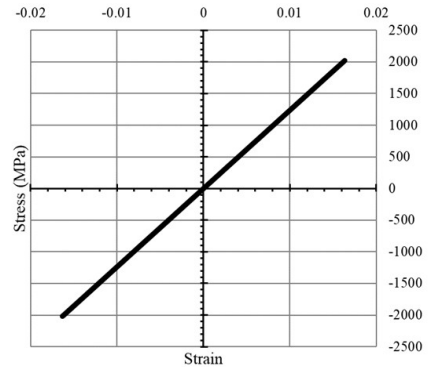

(c) 
Figure 4. Stress-strain models used in fiber element analysis (a) concrete, (b) bilinear model for steel reinforcement, and (c) linear model for CFRP and GFRP bar.

The stress-strain relationship of concrete in compression used in this study was adopted from the model proposed by Mander et al. [15]. For concrete in tension, a linear model up to the maximum tensile strength of the concrete without tensile stiffness is used. The stress-strain relationship for the steel bar used in this study is a bilinear model, while a linear model up to failure is used for CFRP and GFRP bars, as shown in Figure 4(b) and (c).

$$
F_{i}=A_{i} \sigma_{i}
$$

The equilibrium condition is found by adding up all the internal forces. If the equilibrium conditions are not satisfied, the calculation will return to the previous process by changing the strain $\left(\varepsilon_{0}\right)$ on the centroid axis. After the equilibrium condition is met, the moment $(M)$ is obtained by multiplying the internal forces obtained by the distance of each element to the top of the cross-section (Equation 4).

$$
M=\Sigma F_{i} y_{i}
$$

The deflection can be calculated using the curvature at each step. The depth of the neutral axis $(c)$ at each step can be calculated using Equation 5. The analytical calculation process described is assisted by a computer program that the author has developed, and the algorithm of the calculation process can be found in the literature [16-19].

$$
c=\frac{\varepsilon_{c m}}{\mu}
$$

The parametric study in this research was carried out to fill in the gaps in the hybrid reinforcement ratio $\left(A_{f} / A_{s}\right)$ data that were not determined in experimental studies or from the literature. There were 12 specimens in the parametric study with hybrid reinforcement ratios ranging from 1.3 to 4.3 . With this data, it is expected that the behavior of crosssections with higher hybrid reinforcement ratios can be represented. Based on the number of layers of tensile reinforcement, the beam cross-section in the parametric study also consisted of two types as in the experimental research, namely, Type I and Type II. This parametric study used two FRP materials (GFRP and CFRP).

\section{Results and Discussion}

\subsection{Crack Patterns and Failure Modes of the Tested Beams}

The crack pattern and failure model that occurred for each beam are shown in Figure 5. All beams experienced flexural failure, indicated by the concrete crushing at the top of the compression zone. The first flexural crack occurs in the constant moment zone, with an average load level of $5 \mathrm{kN}$ to $8 \mathrm{kN}$.

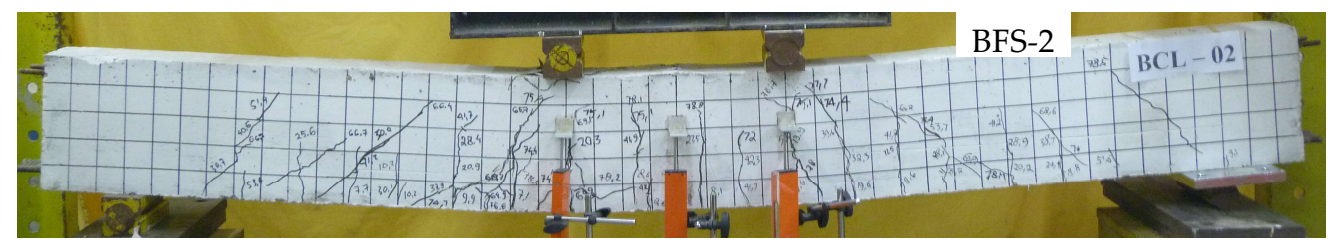

(a) 


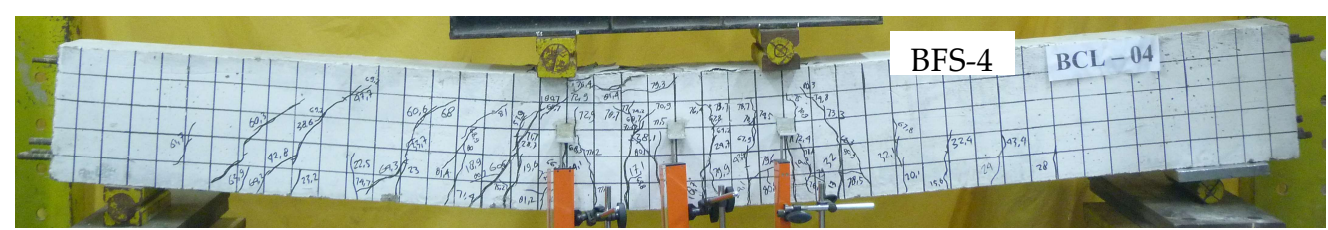

(b)

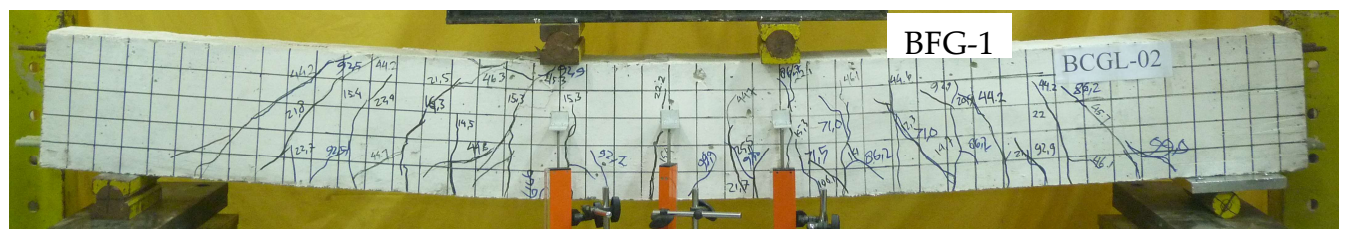

(c)

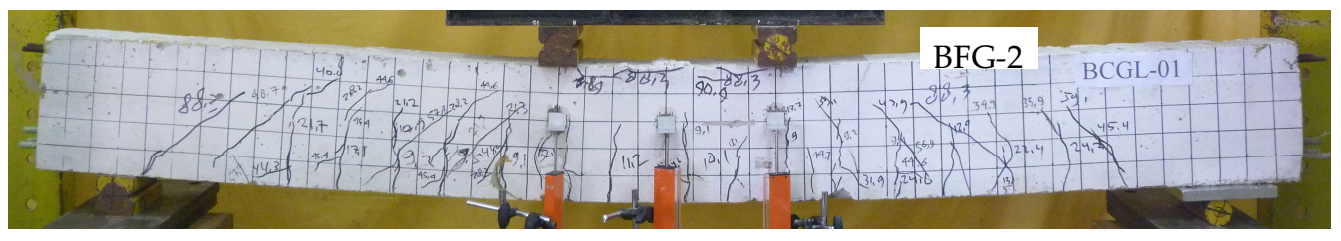

(d)

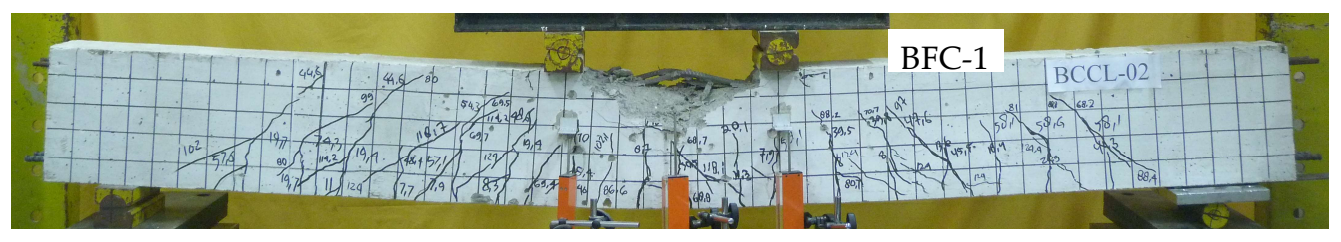

(e)

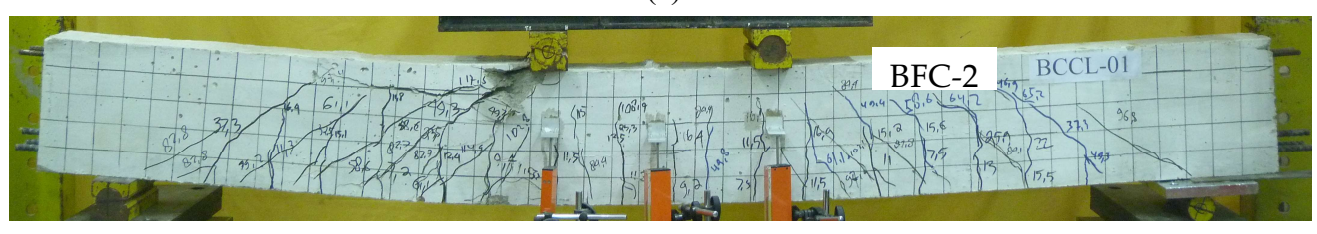

(f)

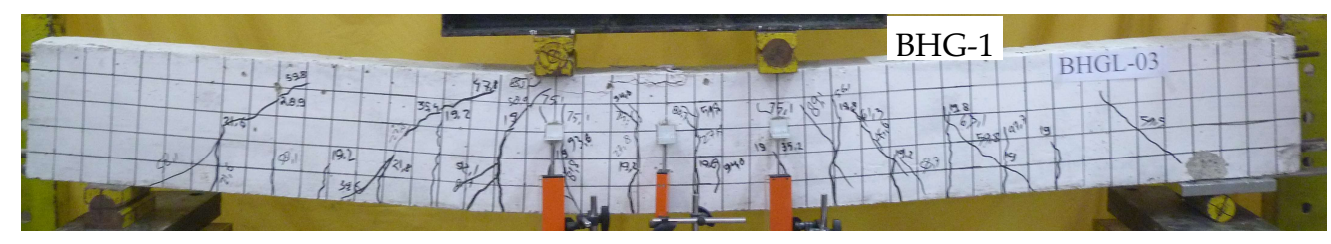

(g)

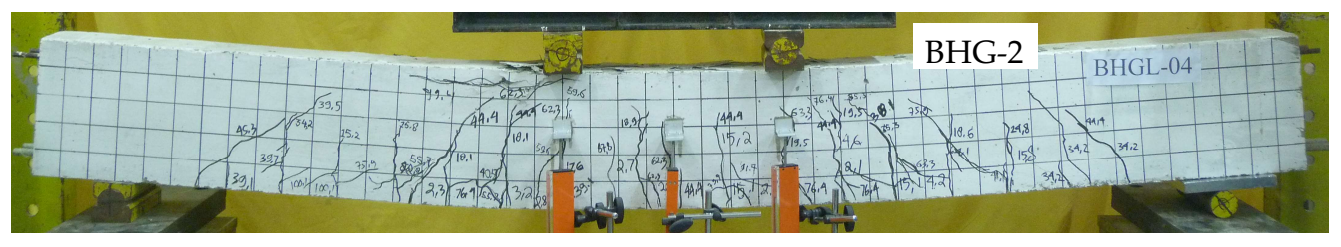

(h) 


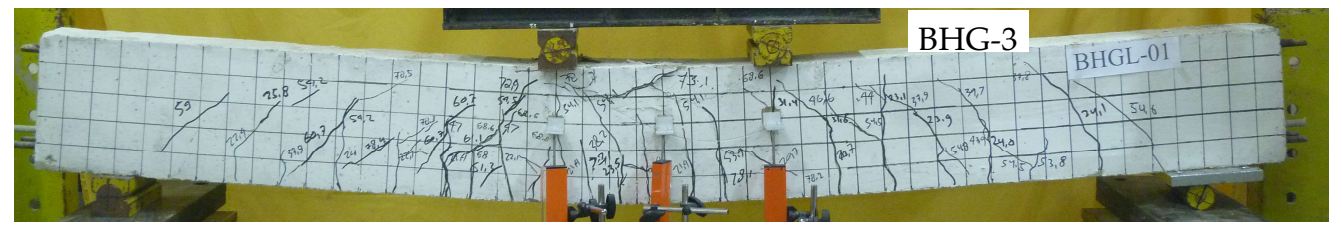

(i)

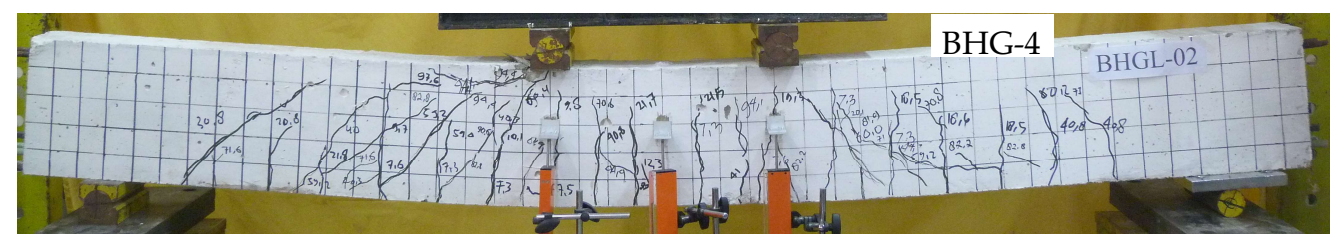

(j)

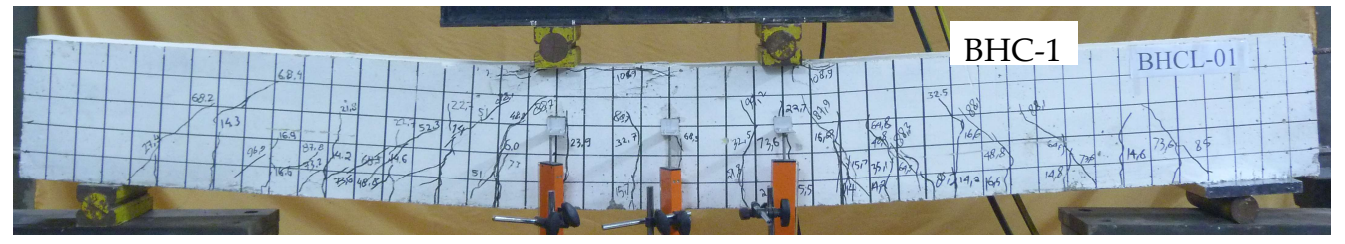

(k)

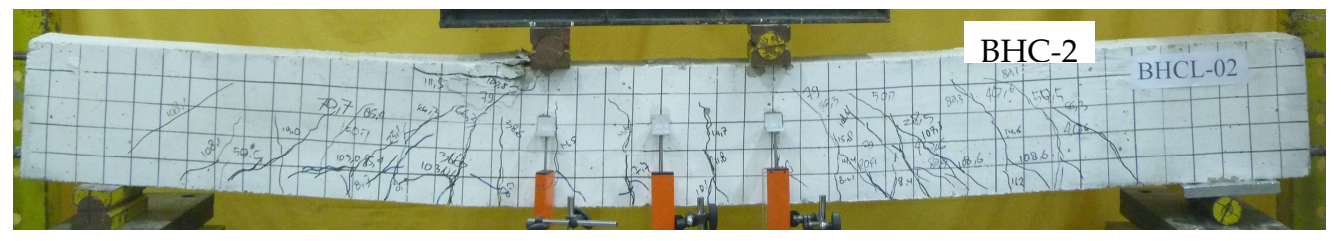

(1)

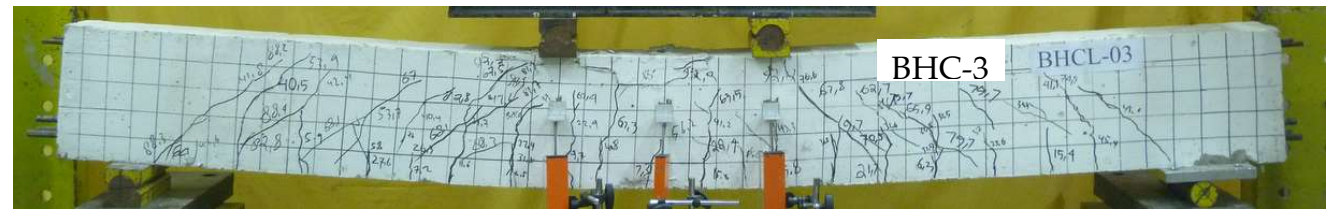

$(\mathrm{m})$

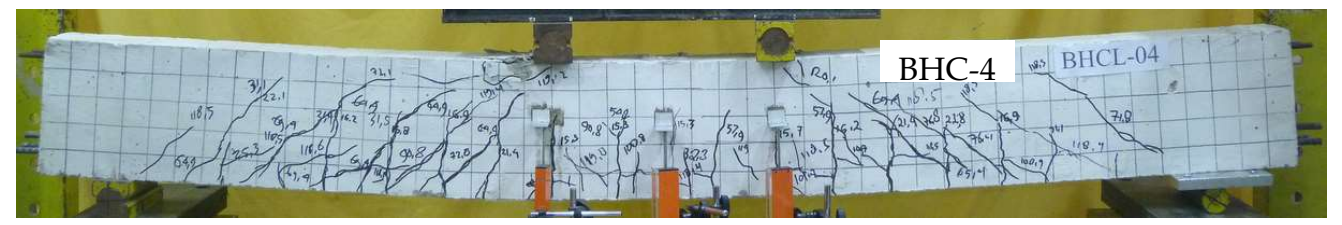

(n)

Figure 5. Typical crack patterns and failure modes of the tested beams (a) BFS-2, (b) BFS-4, (c) BFG-1, (d) BFG-2, (e) BFC-1, (f) BFC-2, (g) BHG-1, (h) BHG-2, (i) BHG-3, (j) BHG-4, (k) BHC-1, (l) BHC-2, (m) BHC-3, and (n) BHC-4.

It is shown from Figure 5 that the height of the flexural crack in the constant moment zone varies according to the hybrid reinforcement ratio $\left(A_{f} / A_{s}\right)$. The higher the hybrid reinforcement ratio, the lower the flexural cracking in the constant moment zone, as shown in Figure 5(j) and 5(n). 
As the load increases, flexural cracks spread to the shear span zone, developing into shear cracks. Inclined cracks are more dominant in beams with a higher hybrid reinforcement ratio. When inclined cracks are formed and propagate towards the load position, the stress at the top of the compression zone increases, and the beams finally reach their ultimate condition. The summary of the failure of the tested beams is shown in Table 2 .

Table 2. The failure mode of the tested beams.

\begin{tabular}{cccc}
\hline Beam Notation & $A_{f} / A_{s}$ & $\begin{array}{c}\text { Type of } \\
\text { Reinforcement }\end{array}$ & Failure Mode \\
\hline BFS-2 & - & Steel & SY, CC \\
BFS-4 & - & Steel & SY, CC \\
BFG-1 & - & GFRP & CC \\
BFG-2 & - & GFRP & CC \\
BFC-1 & - & CFRP & CC \\
BFC-2 & - & CFRP & CC \\
BHG-1 & 0.5 & Steel \& GFRP & SY, CC \\
BHG-2 & 2.0 & Steel \& GFRP & SY, CC \\
BHG-3 & 0.5 & Steel \& GFRP & SY, CC \\
BHG-4 & 2.0 & Steel \& GFRP & SY, CC \\
BHC-1 & 0.5 & Steel \& CFRP & SY, CC \\
BHC-2 & 2.0 & Steel \& CFRP & SY, CC \\
BHC-3 & 0.5 & Steel \& CFRP & SY, CC \\
BHC-4 & 2.0 & Steel \& CFRP & SY, CC \\
\hline Note: & SY $=$ steel yielding & & \\
\hline
\end{tabular}

Different reinforcing materials (GFRP and CFRP) cause significant differences in crack patterns. Cracks in beams with GFRP reinforcement are wider and higher than beams with CFRP reinforcement due to the lower modulus of elasticity of GFRP.

\subsection{Effect of Longitudinal Reinforcement Ratio $\left(A_{f} / A_{s}\right)$}

A load-deflection curve showing the capacity of each beam is plotted in Figure 6. A comparison of the capacities of the non-hybrid beams is shown in Figures 6(a) and 6(b). These figures show different behavior from beams with steel reinforcement to beams with FRP reinforcement. The beam with steel reinforcement demonstrated ductile behavior, while the FRP beam did not. The ductility of beams with steel reinforcement can be seen from the yielding of the tensile reinforcement, which is characterized by a sudden change in stiffness after the elastic limit (after the tensile reinforcement yields) without any significant change in the resistance capacity.

The behavior of the load-deflection curves of beams with hybrid reinforcement can be seen in Figures 6(c) to 6(j). The ductility of beams with hybrid reinforcement is highly dependent on the ratio of hybrid reinforcement $\left(A_{f} / A_{s}\right)$. The ductile behavior of beams with hybrid reinforcement is seen in beams with a small hybrid reinforcement ratio. On the other hand, the ductile behavior becomes less noticeable with a higher hybrid reinforcement ratio even though the steel is yielding. 


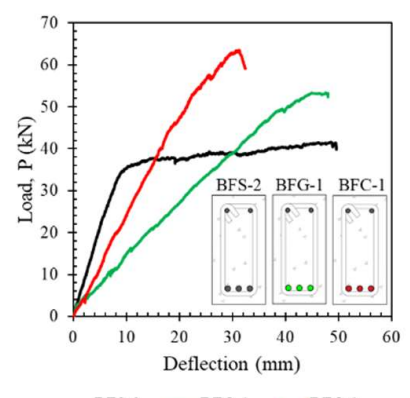

(a)

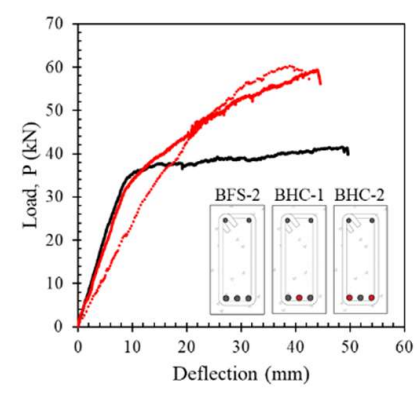

— $\mathrm{BFS}-2$ - ${ }_{\mathrm{BHC}-1} \quad \ldots \ldots . . \mathrm{BHC}-2$

(d)

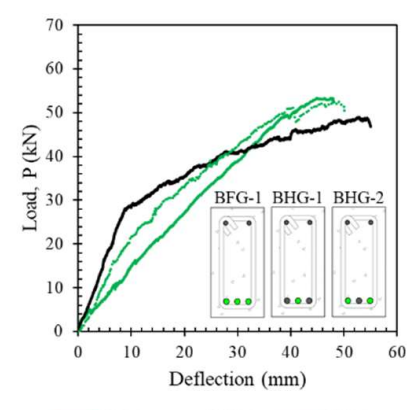

- ${ }_{\text {BFG-1 }}$ - ${ }_{\text {BHG-1 }} \quad \cdots \cdots \cdots$ BHG-2

(g)

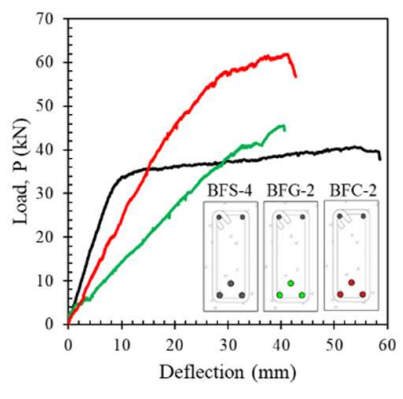

(b)

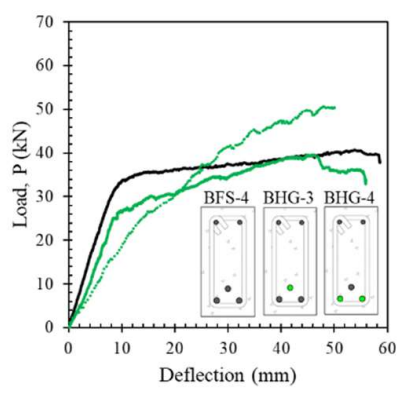

(e)

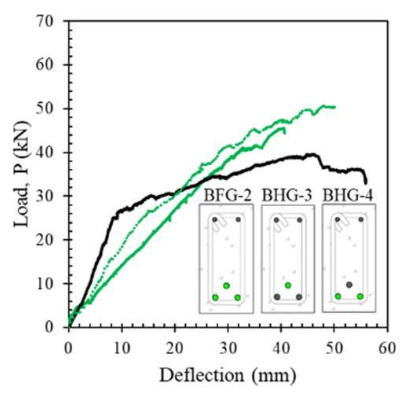

- ${ }_{\text {BFG-2 }}$ - ${ }_{\text {BHG-3 }} \quad$ …… BHG-4

(h)

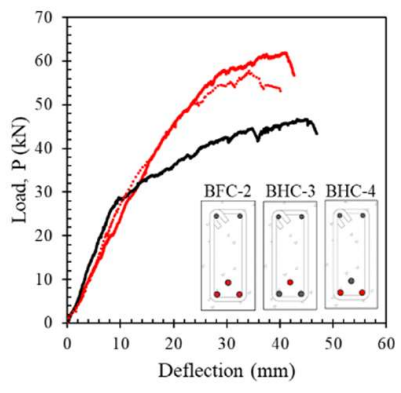

- $\mathrm{BFC}^{-2}-\mathrm{BHC}^{-3} \quad$ …... $\mathrm{BHC}-4$

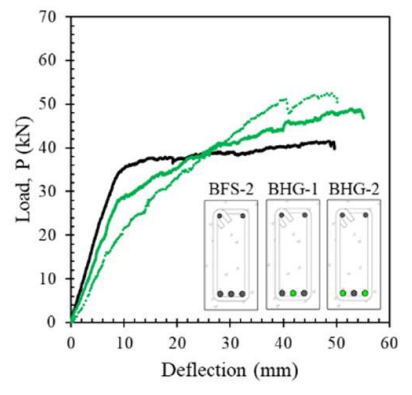

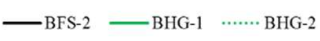

(c)

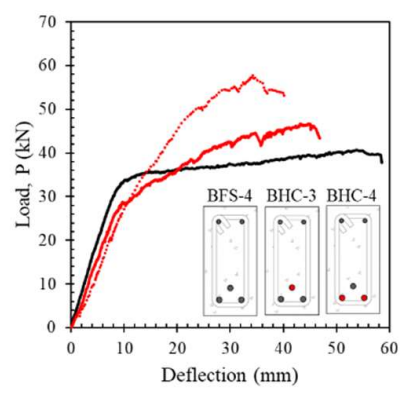

—BFS-4 -

(f)

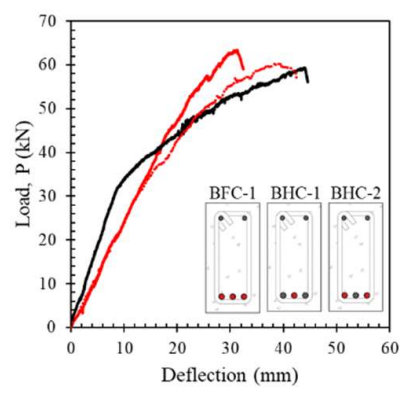

- $\mathrm{BFC}^{-1}$ - $\mathrm{BHC}^{-1} \quad \cdots \cdots \cdots \mathrm{BHC}-2$

(i)

(j)

Figure 6. The load-deflection curves of the tested beams with the effect of hybrid reinforcement ratio. 
Figures 6(c) to 6(j) also show that in beams with a higher hybrid reinforcement ratio (BHG-4 and BHC-4), the yield point of the reinforcing steel is not visible. This causes the process of calculating the beam's ductility to become problematic.

\subsection{Effect of Reinforcement Position}

The effect of the position of the reinforcement on the tested beam is shown in Figure 7. It can be seen that the position of the reinforcement slightly affects the capacity and ductility of the beam. Beams with Type I reinforcement (one layer of reinforcement) show a higher capacity but slightly lower ductility.

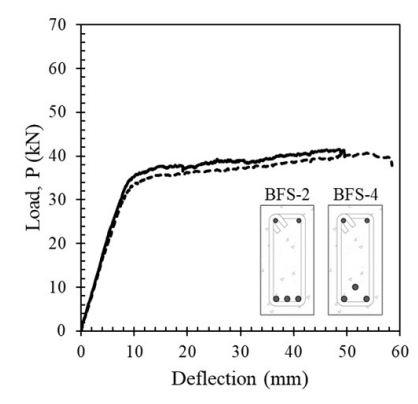

-BFS-2 ----BFS-4

(a)

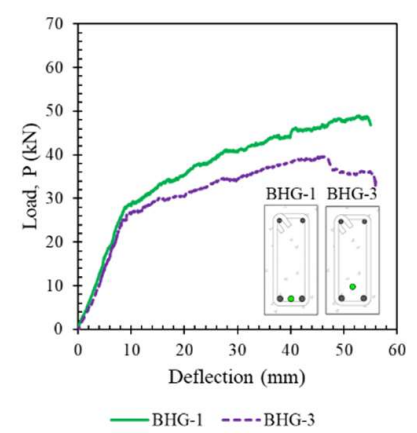

(d)

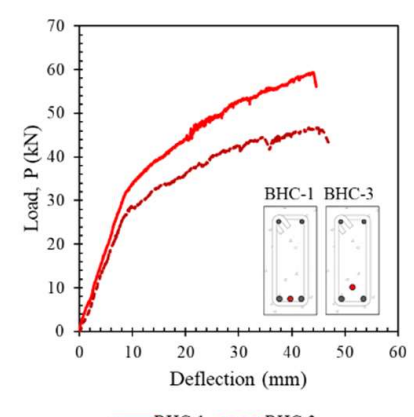

(f)

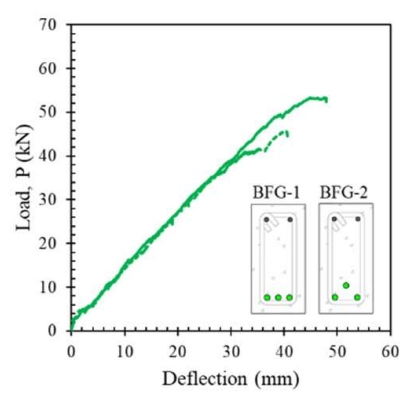

(b)

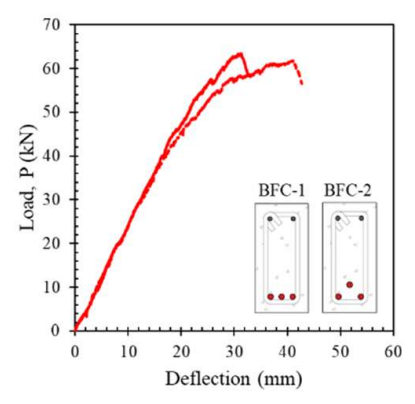

(c)

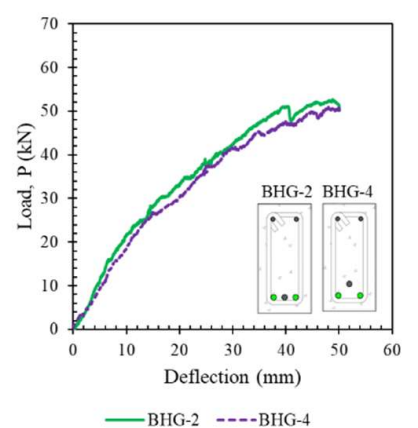

(e)

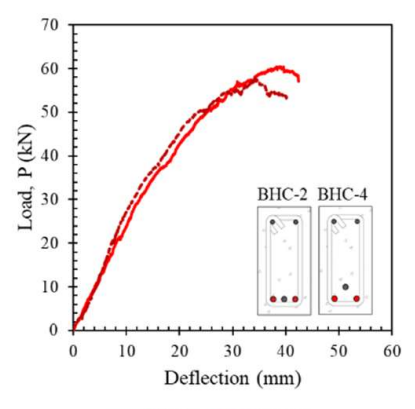

(g)

Figure 7. The load-deflection curves of the tested beams with the effect of bars position.

Figure 7 also shows that the position of the reinforcement and the ratio of the hybrid reinforcement bars affect the slope of the load-deflection curve in the post-elastic zone. This difference is seen in Figures $7(\mathrm{~d})$ to $7(\mathrm{~g})$. The difference in slope in the post-elastic 
zone due to the position of the reinforcement is visible in the beam with a hybrid reinforcement ratio of 0.5 by comparing Figure $7(\mathrm{~d})$ and $7(\mathrm{f})$. However, the beam with the hybrid reinforcement ratio of 2 does not show a significant difference in the slope of the load-deflection curve in the post-elastic zone of steel reinforcement.

\subsection{Strain Distribution in Cross Section with Hybrid Reinforcement}

The strain distributions of the tested beam obtained from the analytical calculations are shown in Figure 8. The notation $y$ on the vertical axis represents the height of each element measured from the top of the cross-section, and the notation $H$ represents the height of the section. It can be seen in the figure that yielding occurs in cross-sections with steel reinforcement because the strain that occurs in the steel reinforcement $\left(\varepsilon_{s}\right)$ has exceeded the yield strain of steel $\left(\varepsilon_{y}\right)$.

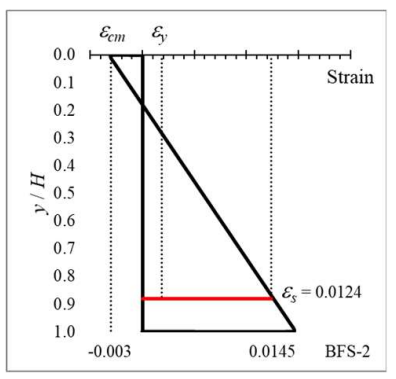

(a)

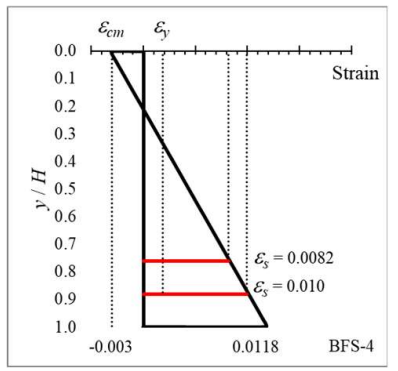

(d)

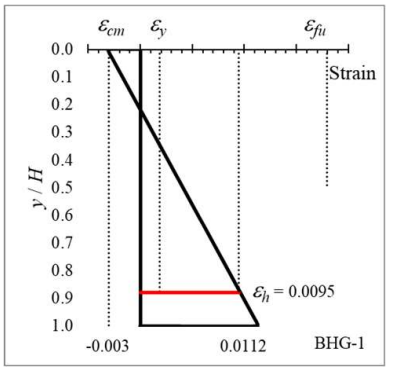

(g)

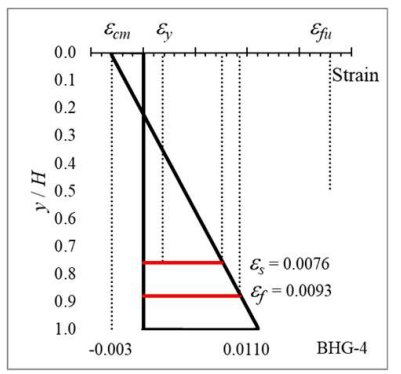

(j)

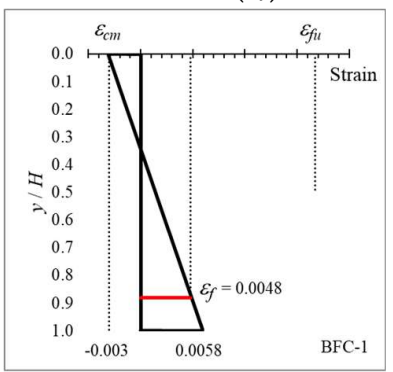

(b)

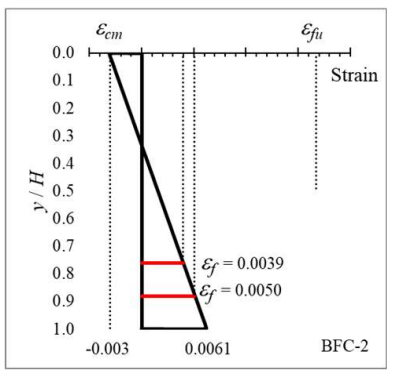

(e)

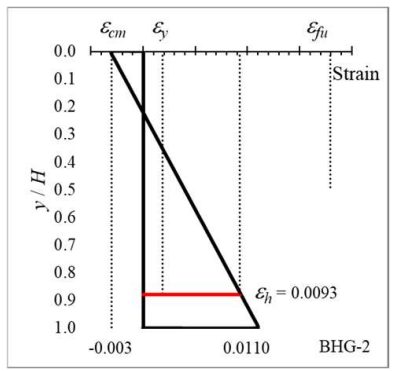

(h)

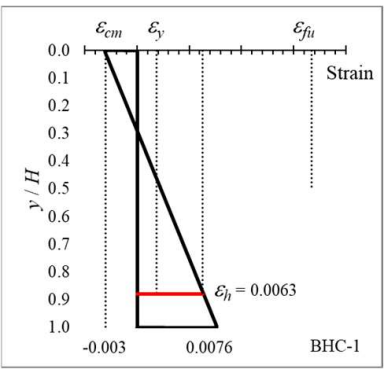

(k)

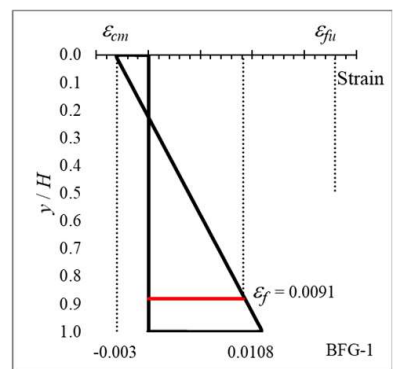

(c)

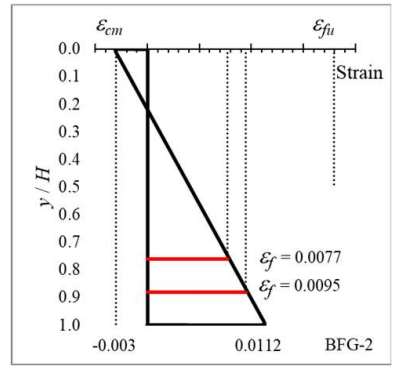

(f)

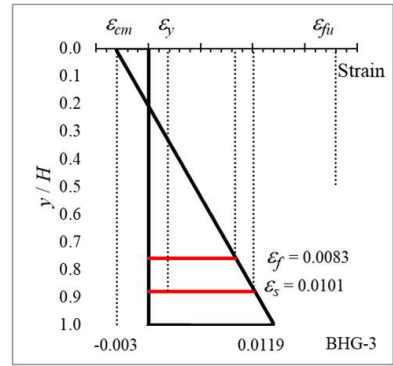

(i)

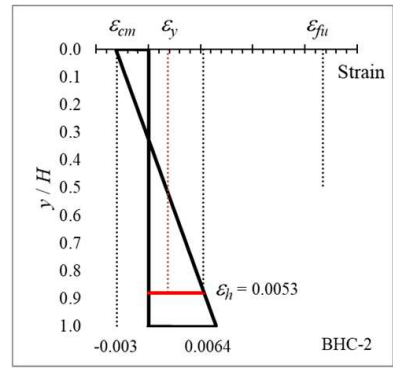

(1) 


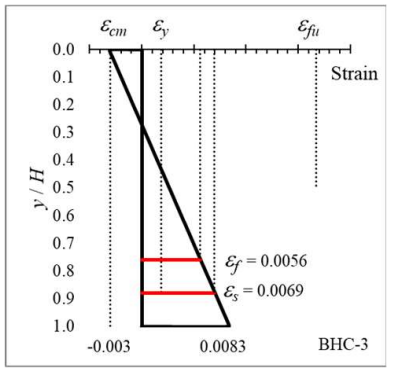

(m)

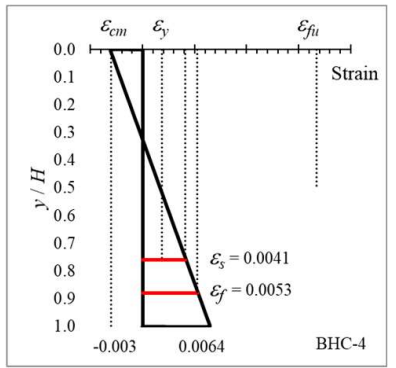

(n)

Figure 8. Strain distribution of the tested beams obtained analytically (a) BFS-2, (b) BFC-1, (c) BFG-1, (d) BFS-4, (e) BFC-2, (f) BFG-2, (g) BHG-1, (h) BHG-2, (i) BHG-3, (j) BHG-4, (k) BHC-1, (l) BHC-2, (m) BHC-3, and (n) BHC-4.

The maximum strain in FRP reinforcement $\left(\varepsilon_{f}\right)$ in all beam sections did not exceed the ultimate tensile strength $(\varepsilon f u)$. This result agrees with the beam test results obtained from experimental studies. In cross-sectional analysis with the fiber element method, the maximum compressive strain entered into the computer program is 0.003 , which agrees with experimental tests where all beams are crushed in the compression zone.

In the cross-section with steel reinforcement, the maximum strain at the Type I section is greater than the Type II section. However, this does not happen in the FRP-reinforced and hybrid-reinforced sections. This indicates that the position of the reinforcement affects the cross-sectional strain distribution. In addition, the different types of FRP also have a significant influence on the strain distribution where the cross-section with GFRP reinforcement experiences a higher strain. This is due to the lower modulus of elasticity of GFRP compared to steel and CFRP.

\subsection{Neutral Axis Growth in Cross Section with Hybrid Reinforcement}

As stated in the previous section, the process of calculating the ductility from the load-deflection curve becomes more difficult as the hybrid reinforcement ratio increases because the exact position at which the steel reinforcement yield becomes unclear. In this study, the authors propose a method to determine the yield position of steel reinforcement in a cross-section of reinforced concrete beams with hybrid reinforcement. The proposed method uses an analytically obtained neutral axis curve calculated using Equation 5. However, before being applied for this purpose, the calculated neutral axis curve results were verified with experimental data obtained from the literature [20] and the results of other software calculations [21].

Figures 9 and 10 compare the neutral axes calculated by Equation 5 from experimental data obtained from the literature and the results of other software. These comparisons show that the neutral axis calculated by Equation 5 is very close to the experimental data results and computed using other software. This indicates that the neutral axis calculated by Equation 5 can be used to determine the position of the yield point of the steel reinforcement in the cross-section of reinforced concrete with hybrid reinforcement. 


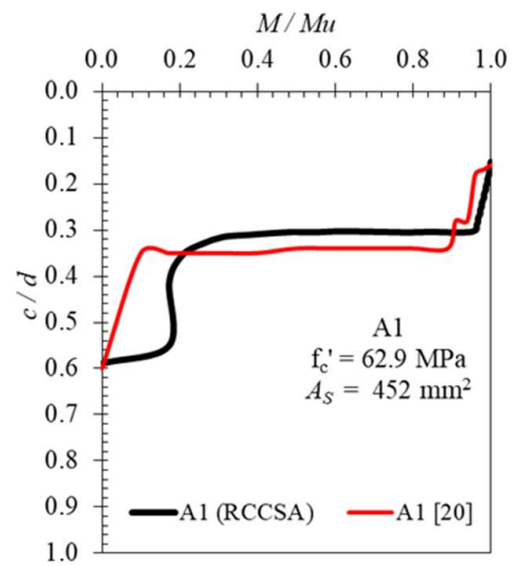

(a)

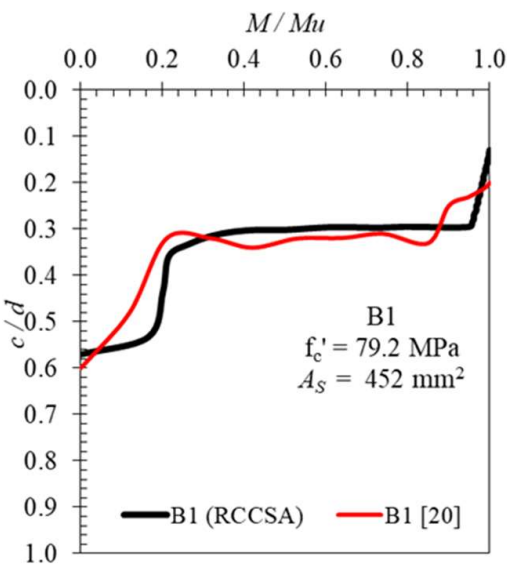

(b)

Figure 9. Verification of calculated neutral axis curve with adopted (a) experimental data A1 and (b)

B1 [20].

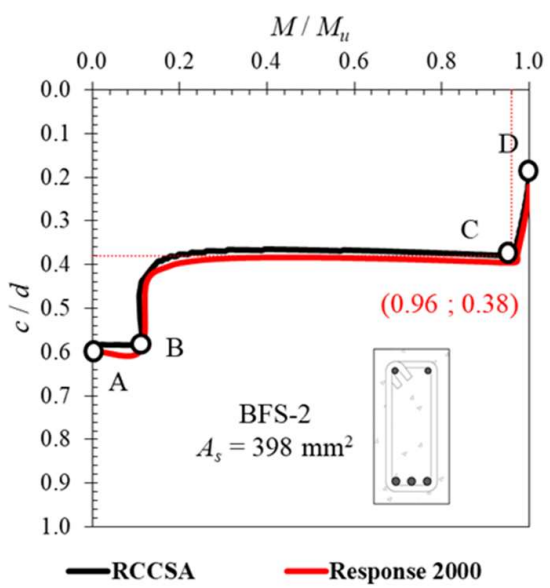

(a)

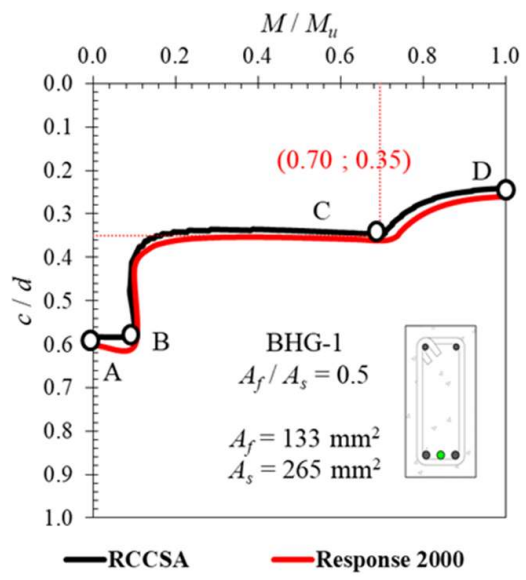

(b)

Figure 10. Verification of calculated neutral axis curve with other software [21] for the specimen (a) BFS-2 and (b) BHG-1.

Figure 11 shows the neutral axis curves obtained analytically from the tested reinforced concrete beam sections. In all beam cross-sections, the movement of the neutral axis starts from Point $A$ to Point $B$. This range is the zone before the first crack in the section. After that, the neutral axis moves towards Point $C$, which is a point that indicates the reinforcing steel has yielded. In the cross-section with steel reinforcement (BFS-2 and BFS4 ), Point $C$ is very clearly visible, followed by a steep slope of inclination towards Point $D$, which indicates movement after the elastic zone of the steel. 


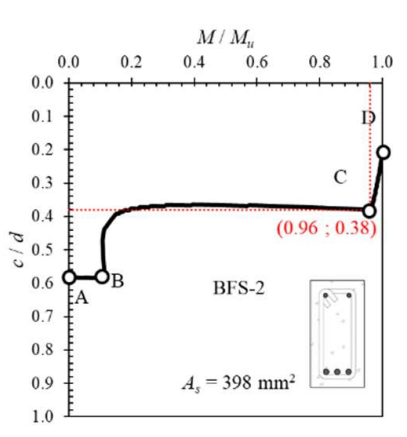

(a)

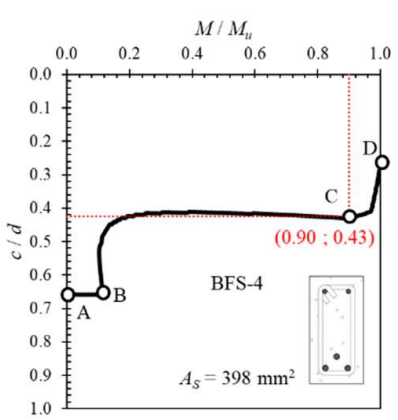

(d)

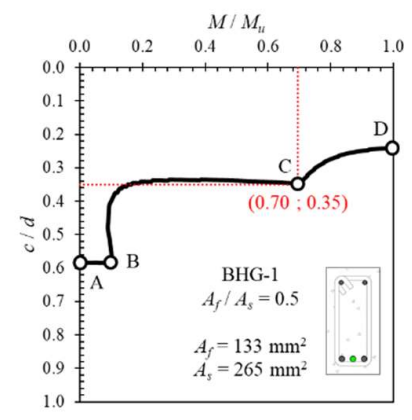

(g)

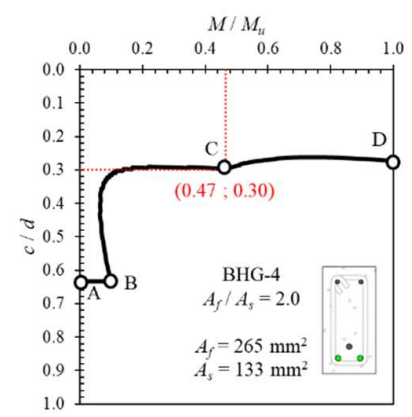

(j)

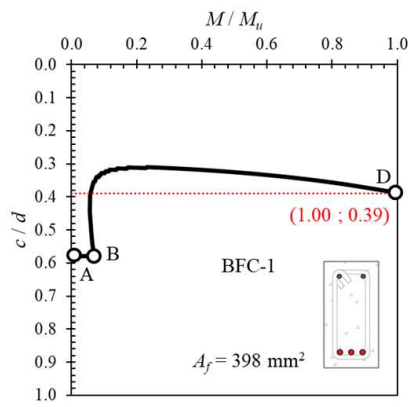

(b)

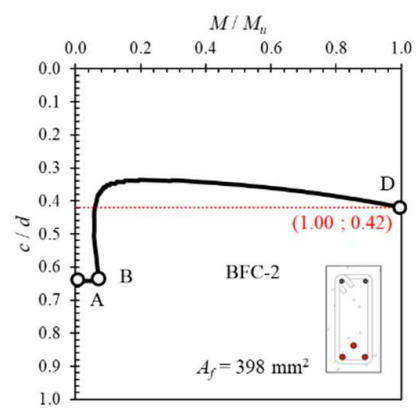

(e)

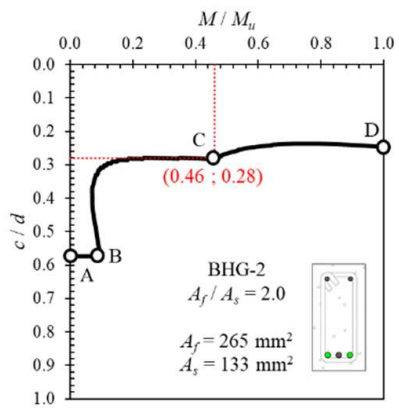

(h)

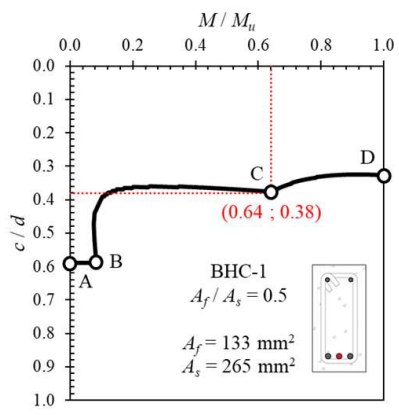

(k)

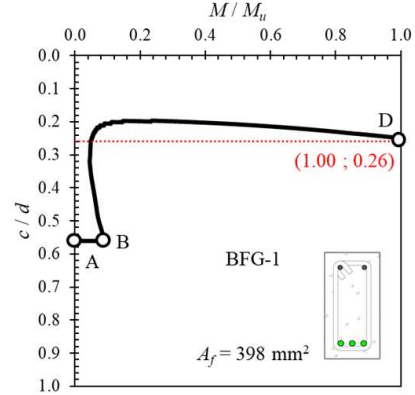

(c)

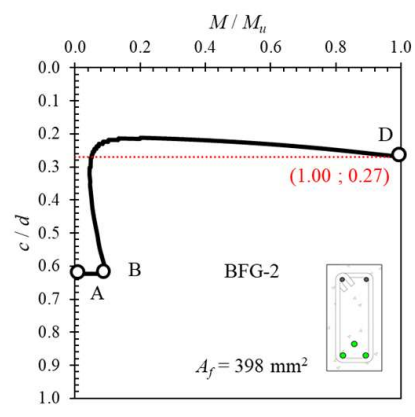

(f)

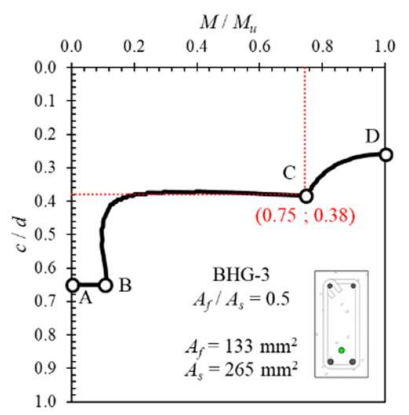

(i)

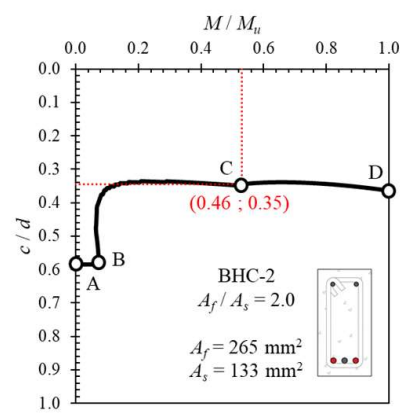

(1) 


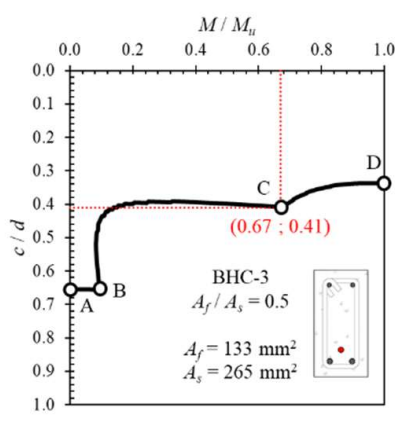

(m)

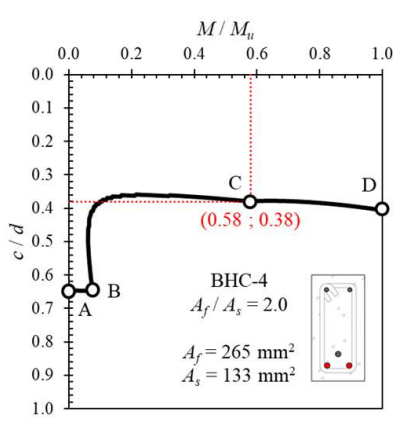

(n)

Figure 11. The neutral axis curve of the tested beams obtained analytically (a) BFS-2, (b) BFC-

1, (c) BFG-1, (d) BFS-4, (e) BFC-2, (f) BFG-2, (g) BHG-1, (h) BHG-2, (i) BHG-3, (j) BHG-4, (k) BHC-1, (l) BHC-2, (m) BHC-3, and (n) BHC-4.

On the other hand, Point $C$ (yield point) is not found in the cross-section with only FRP reinforcement (BFC-1, BFC-2, BFG-1, and BFG-2). In the section with FRP reinforcement only, the neutral line moves towards the ultimate point without any post-elastic behavior of the reinforcement after Point $B$.

In cross-sections with hybrid reinforcement, Point $C$ is followed by a post-elastic zone where the angle of inclination depends on the ratio of the hybrid reinforcement. The larger the hybrid reinforcement ratio, the smaller the angle of inclination of the curve after Point $C$. In this study, Point $C$ is used as a reference to help determine the yield point in sections with large hybrid reinforcement ratios.

In general, the movement of the neutral axis can be summarized in Figure 12. The neutral axis curve of specimens BFS-2, BFC-1, BFG-1, BHG-1, and BHC-1 are plotted to demonstrate the zones and essential points. It can be seen that the starting point of the neutral axis starts from about the middle of the cross-sectional height (Point A). The movement of the neutral axis does not show a significant change until the cross-section experiences the first flexural crack (Point $B$ ). After flexural cracking occurs, the neutral axis moves rapidly towards the top of the cross-section.

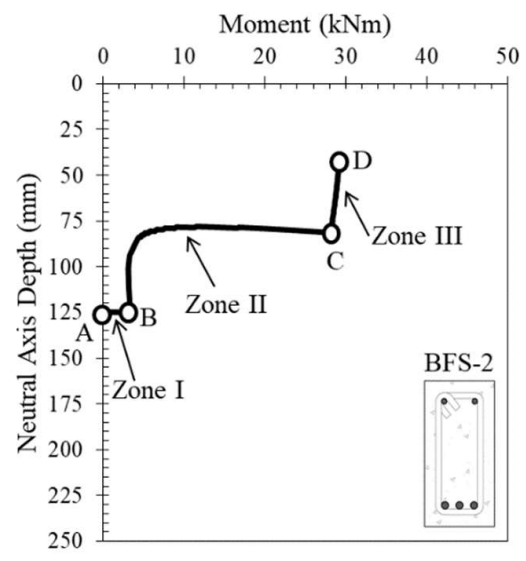

(a)

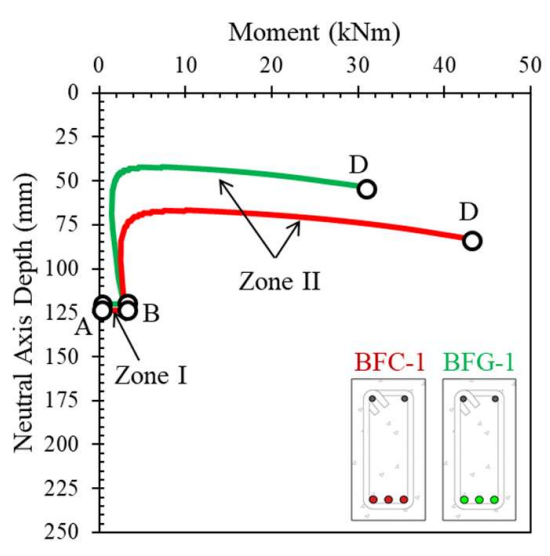

(b) 


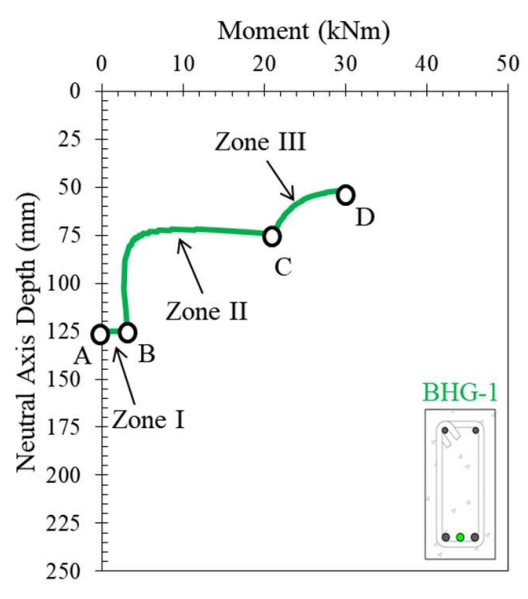

(c)

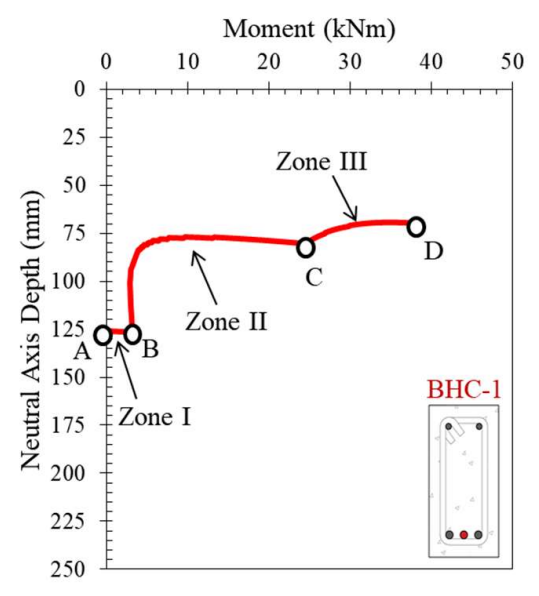

(d)

Figure 12. Typical neutral axis curve of reinforced concrete beams cross-section with (a) steel reinforcement, (b) FRP reinforcement, (c) hybrid steel-GFRP reinforcement, and (d) hybrid steel-CFRP reinforcement.

In the cross-section with steel reinforcement, the neutral axis moves to Point $C$, representing the steel's yielding. In an over-reinforced cross-section with steel bars, the tensile reinforcement in the cross-section does not experience yielding. After point $B$, the curve goes straight to and stops at Point $D$. This phenomenon is also seen in all neutral axis curves in the cross-section with FRP reinforcement, indicating that the inelastic deformation of steel reinforcement affects the movement of the neutral axis and the ductility of the cross-section.

Figure 12 shows that, during loading, the curve of the neutral axis can be divided into three zones, as shown in Figure 12(a), especially in sections with under-reinforced steel reinforcement. However, with an over-reinforced cross-section (yielding of the reinforcement does not occur), there are only two parts to the curve, with the end of the curve having a downward slope before reaching the ultimate condition. In this condition, the section fails in compression, characterized by crushing the concrete in the compression area with the reinforcement still in an elastic state. A similar situation also occurs in sections with under or over-reinforced FRP reinforcement, as shown in Figure 12(b).

The behavior of the neutral axis curve on a reinforced concrete cross-section with hybrid reinforcement is shown in Figures 12(c) and (d). There are three zones on these curves, namely the zone before cracking ( $A$ to $B$ ), the zone after cracking $(B$ to $C$ ), and the zone after yielding $(C$ to $D)$. The angle of inclination $(\alpha)$ after Point $C$ depends on the type of FRP used and the hybrid reinforcement ratio.

\subsection{Ductility of Cross Section with Hybrid Reinforcement}

The process of calculating the ductility of the beam with and without hybrid reinforcement was carried out using the load-deflection curve shown in Figure 13 and Equation 6. Because it is difficult to determine the position of yield loads $\left(P_{y}\right)$ visually, the position of $P_{y}$ for beams with hybrid cross-section and large ratio of hybrid reinforcement (BHG-2, BHG-4, BHC-2, and BHC-4) were determined using the neutral axis curve shown in Figure 11 above. The yield position of the hybrid cross-section reinforcement with a high hybrid reinforcement ratio can be seen as shown at point $C$ on the neutral axis curve. The calculated ductility values are presented in Table 3 .

$$
\delta=\frac{\Delta_{u}}{\Delta_{y}}
$$




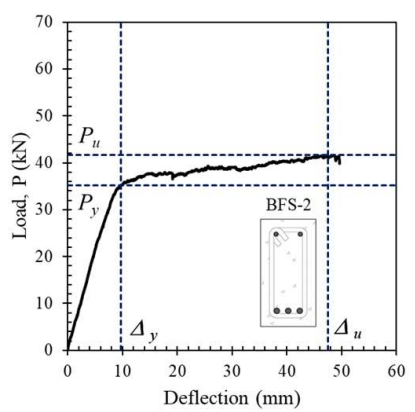

(a)

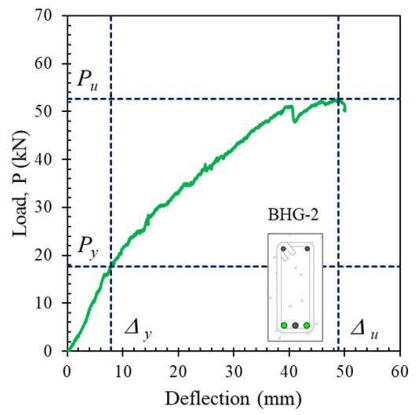

(d)

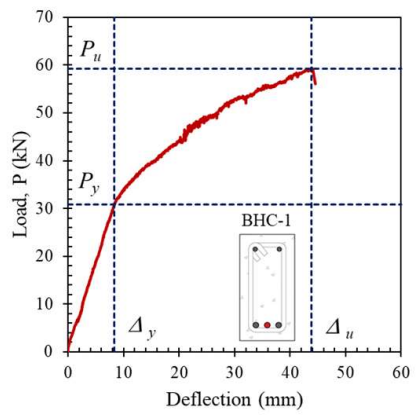

(g)

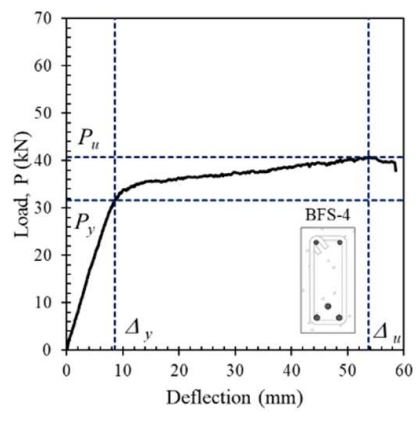

(b)

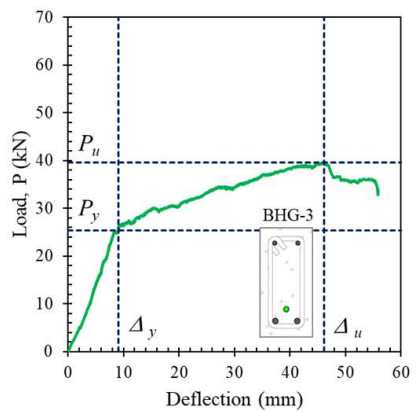

(e)

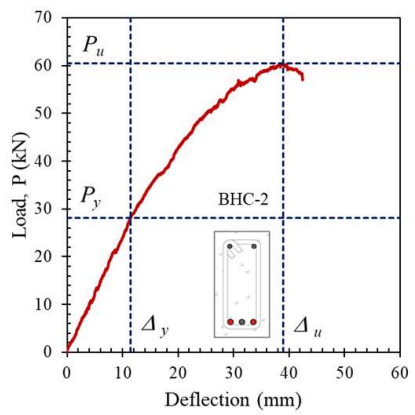

(h)

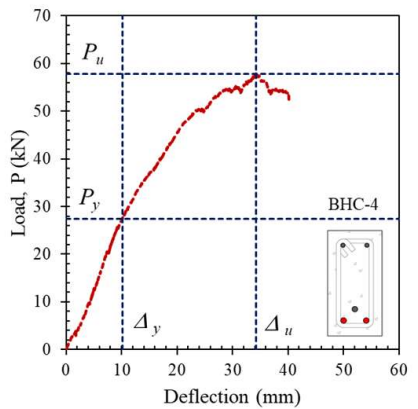

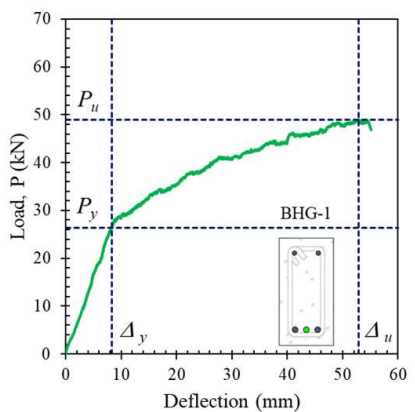

(c)

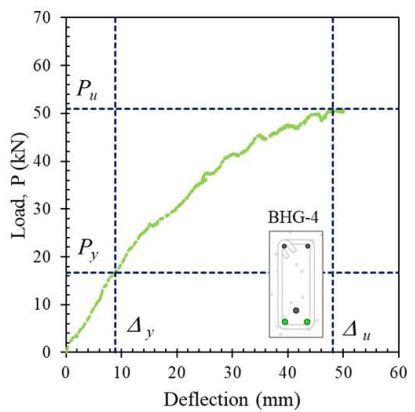

(f)

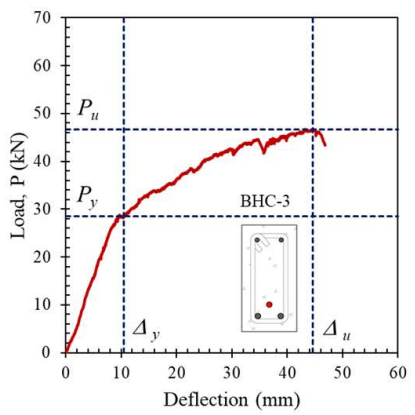

(i)

(j)

Figure 13. The process of determining the ductility of the tested beam (a) BFS-2, (b) BFS-4, (c) BHG-1, (d) BHG-2, (e) BHG-3, (f) BHG-4, (g) BHC-1, (h) BHC-2, (i) BHC-3, and (j) BHC-4. 
Figure 14 shows the effect of the hybrid reinforcement ratio $\left(A_{f} / A_{s}\right)$ on the ductility $(\delta)$ of the tested beams and the data obtained from the literature. The ratio of hybrid reinforcement used in the specimens (experimental and parametric) and data obtained from the literature ranged from 0.3 to 4.3 with three types of FRP bars (Aramid, CFRP, and GRP). The red line shows the trend of the data showing a decrease in ductility with increasing the hybrid reinforcement ratio. The vertical shaded area in Figure 14 indicates the hybrid reinforcement ratio zone from 1 to 2.5 . This zone is the recommended hybrid reinforcement ratio zone to ensure the beam has sufficient ductility and stiffness after exceeding the elastic phase [9].

Meanwhile, the horizontally shaded area is the adequate ductility suggested in this study for the cross-section with hybrid reinforcement with a value greater than 4 . Statistical analysis using correlation coefficient was used to see the strength of the linear relationship between the variables hybrid reinforcement ratio $\left(A_{f} / A_{s}\right)$ and the ductility $(\delta)$. The results showed a relationship with a moderate correlation value $(R)$ of -0.38 , where the minus sign means that the value of the hybrid reinforcement ratio increases and the ductility value decreases.

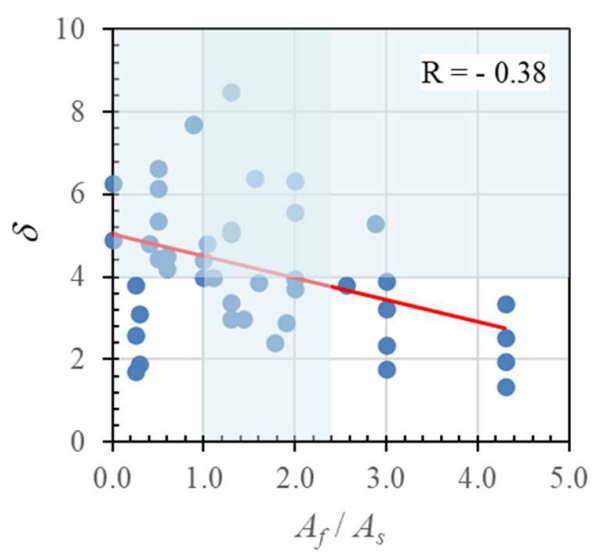

Figure 14. Relationship between hybrid reinforcement ratio $\left(A_{f} / A_{s}\right)$ and ductility $(\delta)$ of the tested beams, parametric study, and data obtained from the literature.

\subsection{Neutral Axis Angle ( $\alpha$ ) and Neutral Axis Displacement Index ( $\left.\delta_{\mathrm{N}}\right)$}

A neutral axis angle $(\alpha)$ and neutral axis displacement index $\left(\delta_{\mathrm{N}}\right)$ obtained from the neutral axis curve profile are introduced in this paper as an alternative method to evaluate the ductility of the reinforced concrete section with hybrid reinforcement. The definition of the neutral axis angle in this paper is the angle formed at Point C (see Figure 15), which occurs after the steel reinforcement has yielded. The neutral axis angle can be calculated using Equation 7 and with the help of Figure 15. The value of this angle indicates the change in stiffness of the section after the steel reinforcement yield. A positive angle value means Point $\mathrm{D}$ is above Point $\mathrm{E}$ and vice versa. The greater the value of the neutral axis angle, the greater the ductility value.

Meanwhile, the neutral axis displacement index $\left(\delta_{\mathrm{N}}\right)$ value can be calculated using Equation 8. This value indicates the journey of the neutral line from Point A to Point D. An index value greater than 1 indicates Point $D$ is above Point $E$, and the index value is smaller than one means Point D is below Point E. The greater the neutral axis displacement index value, the greater the ductility value. Calculated neutral axis angles and neutral axis displacement index obtained from experimental data, parametric studies, and literature are shown in Table 3, Figure 16, and Figure 17. 


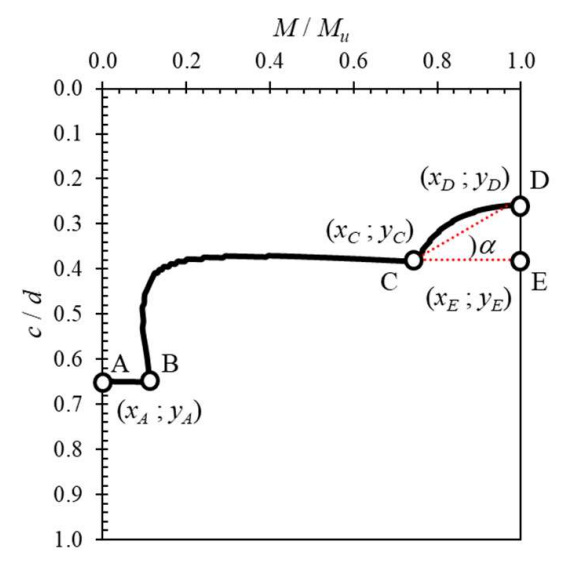

Figure 15. Illustration of neutral axis angle $(\alpha)$ and neutral axis displacement index $\left(\delta_{\mathrm{N}}\right)$ determination.

$$
\begin{gathered}
\tan \alpha=\frac{y_{E}-y_{D}}{x_{E}-x_{C}} \\
\delta_{N}=\frac{y_{A}-y_{D}}{y_{A}-y_{E}}
\end{gathered}
$$

The neutral axis angle $(\alpha)$ is plotted against the hybrid reinforcement ratio $\left(A_{f} / A_{s}\right)$ in Figure 16. It can be seen that the neutral axis angle decreases with the increase of the hybrid reinforcement ratio. This result is in accordance with the observation in the previous section that the ductility decreases with the increase in the hybrid reinforcement ratio.

The neutral axis angle data plotted in Figure 16 are combined in Figure 17(a). The red line shows the data trend, and the data has a significant negative correlation value $(R)$ of -0.67. Figure $17(\mathrm{~b})$ shows the relationship between the hybrid reinforcement ratio $\left(A_{f} / A_{s}\right)$ and the neutral axis displacement index $\left(\delta_{\mathrm{N}}\right)$. The data has a relatively strong negative correlation value of -0.83 . The value of the neutral axis displacement index decreases as the value of the hybrid reinforcement ratio increases.

The neutral axis angle and the neutral axis displacement index are plotted in Figure 17(c) to show the correlation between the two variables. The data has a relatively strong positive correlation value of 0.89 . This proves that these two variables have a reasonably strong relationship.

Furthermore, the relationship between the neutral axis displacement index and ductility is shown in Figure 17(d). The data shows a weak positive (negative) linear relationship with a correlation value of 0.26 . However, these data indicate that the ductility value increases with the increase in the neutral axis displacement index value.

Table 3. Ductility $(\delta)$, neutral axis angle $(\alpha)$, yield moment, ultimate moment, and deformability factor ( $D F$ mod $)$ of the crosssection with hybrid reinforcement.

\begin{tabular}{cccccccccccc}
\hline $\begin{array}{c}\text { Beam } \\
\text { Notation }\end{array}$ & $A_{f} / A_{s}$ & $\delta$ & $\alpha$ & $\delta_{N}$ & $\begin{array}{c}M_{y} \\
(\mathbf{k N m})\end{array}$ & $\mu_{y}$ & $\begin{array}{c}\boldsymbol{M}_{u} \\
\mathbf{( k N m )}\end{array}$ & $\mu_{u}$ & $\boldsymbol{D F}$ & $\begin{array}{c}\text { Type of } \\
\text { FRP }\end{array}$ & $\begin{array}{c}\text { Type of } \\
\text { Cross- } \\
\text { section }\end{array}$ \\
\hline \multicolumn{10}{c}{ Data from this study [Experimental] } \\
\hline BFS-2 & - & 4.9 & 77.7 & 1.7 & 28.2 & 1.4 & 29.1 & 7.2 & 5.4 & - & Type I \\
BFS-4 & - & 6.3 & 58.8 & 1.6 & 25.1 & 1.4 & 27.4 & 6.0 & 4.8 & - & Type II \\
BFG-1 & - & - & - & - & - & - & - & - & - & GFRP & Type I \\
BFG-2 & - & - & - & - & - & - & - & - & - & GFRP & Type II
\end{tabular}




\begin{tabular}{|c|c|c|c|c|c|c|c|c|c|c|c|}
\hline BFC-1 & - & - & - & - & - & - & - & - & - & CFRP & Type I \\
\hline BFC-2 & - & - & - & - & - & - & - & - & - & CFRP & Type II \\
\hline BHG-1 & 0.5 & 6.6 & 19.6 & 1.4 & 21.2 & 1.3 & 29.9 & 5.8 & 6.4 & GFRP & Type I \\
\hline BHG-2 & 2.0 & 6.3 & 3.6 & 1.1 & 14.2 & 1.2 & 30.4 & 5.7 & 9.9 & GFRP & Type I \\
\hline BHG-3 & 0.5 & 6.1 & 25.7 & 1.4 & 20.6 & 1.3 & 27.2 & 6.1 & 6.0 & GFRP & Type II \\
\hline BHG-4 & 2.0 & 5.6 & 2.8 & 1.1 & 13.6 & 1.5 & 28.9 & 5.7 & 8.2 & GFRP & Type II \\
\hline BHC-1 & 0.5 & 5.4 & 8.5 & 1.2 & 24.4 & 1.4 & 38.1 & 4.3 & 4.9 & CFRP & Type I \\
\hline BHC-2 & 2.0 & 3.7 & -2.4 & 0.9 & 21.2 & 1.3 & 41.4 & 3.9 & 5.7 & CFRP & Type I \\
\hline BHC-3 & 0.5 & 4.5 & 12.2 & 1.3 & 22.7 & 1.4 & 33.4 & 4.6 & 4.9 & CFRP & Type II \\
\hline BHC-4 & 2.0 & 4.0 & -3.6 & 0.9 & 23.1 & 1.7 & 39.9 & 3.9 & 3.9 & CFRP & Type II \\
\hline \multicolumn{12}{|c|}{ Data from this study [Parametric] } \\
\hline BHG-5 & 3.0 & 3.9 & 1.5 & 1.0 & 15.9 & 1.2 & 34.6 & 4.9 & 8.7 & GFRP & Type I \\
\hline BHG-6 & 3.0 & 3.2 & 0.5 & 1.0 & 15.7 & 1.5 & 33.1 & 4.9 & 6.9 & GFRP & Type II \\
\hline BHG-7 & 4.3 & 3.3 & -0.8 & 1.0 & 18.4 & 1.3 & 38.3 & 4.3 & 7.0 & GFRP & Type I \\
\hline BHG-8 & 4.3 & 2.5 & -1.2 & 1.0 & 19.2 & 1.6 & 36.8 & 4.3 & 5.2 & GFRP & Type II \\
\hline BHG-9 & 1.3 & 5.1 & 7.0 & 1.2 & 14.7 & 1.2 & 28.7 & 6.1 & 9.6 & GFRP & Type I \\
\hline BHG-10 & 1.3 & 5.2 & 9.4 & 1.2 & 13.9 & 1.3 & 24.6 & 6.5 & 9.0 & GFRP & Type II \\
\hline BHC-5 & 3.0 & 2.3 & -4.8 & 0.9 & 26.8 & 1.4 & 45.9 & 3.3 & 4.0 & CFRP & Type I \\
\hline BHC-6 & 3.0 & 1.8 & -6.6 & 0.9 & 15.7 & 1.5 & 33.1 & 4.9 & 6.9 & CFRP & Type II \\
\hline BHC-7 & 4.3 & 2.0 & -7.1 & 0.8 & 33.6 & 1.6 & 49.6 & 2.9 & 2.7 & CFRP & Type I \\
\hline BHC-8 & 4.3 & 1.3 & -7.8 & 0.8 & 38.8 & 2.1 & 48.1 & 2.9 & 1.7 & CFRP & Type II \\
\hline BHC-9 & 1.3 & 3.0 & 0.7 & 1.0 & 19.7 & 1.3 & 38.9 & 4.2 & 6.5 & CFRP & Type I \\
\hline BHC-10 & 1.3 & 3.4 & 2.6 & 1.1 & 17.3 & 1.3 & 32.6 & 4.6 & 6.7 & CFRP & Type II \\
\hline \multicolumn{12}{|c|}{ Aiello et al. [1] } \\
\hline A1 & 0.9 & 7.7 & 3.6 & 1.1 & 8.8 & 1.9 & 20.2 & 11.9 & 14.4 & AFRP & Type II \\
\hline $\mathrm{A} 2$ & 1.6 & 6.4 & 3.1 & 1.1 & 10.4 & 1.9 & 25.8 & 10.0 & 12.7 & AFRP & Type II \\
\hline A3 & 1.0 & 4.8 & 8.7 & 1.1 & 20.0 & 2.2 & 34.1 & 7.6 & 5.8 & AFRP & Type II \\
\hline $\mathrm{C} 1$ & 0.9 & 7.7 & 11.2 & 1.1 & 9.7 & 1.8 & 21.2 & 11.9 & 14.5 & AFRP & Type I \\
\hline \multicolumn{12}{|c|}{ Qu et al. [3] } \\
\hline B3 & 1.1 & 4.0 & 6.9 & 1.2 & 20.7 & 1.2 & 46.0 & 7.5 & 14.0 & GFRP & Type I \\
\hline B4 & 2.0 & 2.9 & 4.9 & 1.1 & 19.5 & 1.1 & 49.9 & 6.7 & 16.0 & GFRP & Type I \\
\hline B5 & 0.4 & 4.8 & 21.5 & 1.4 & 28.4 & 1.1 & 43.4 & 8.4 & 11.4 & GFRP & Type I \\
\hline B6 & 0.6 & 4.5 & 14.7 & 1.3 & 30.4 & 1.2 & 51.9 & 6.6 & 9.5 & GFRP & Type I \\
\hline B7 & 1.3 & 8.5 & 7.3 & 1.2 & 10.7 & 1.1 & 30.8 & 10.5 & 27.0 & GFRP & Type I \\
\hline B8 & 0.3 & 3.1 & 38.3 & 1.4 & 77.6 & 1.6 & 87.3 & 3.7 & 2.7 & GFRP & Type II \\
\hline \multicolumn{12}{|c|}{ Lau \& Pam [4] } \\
\hline G0.3- & & & & & & & & & & & \\
\hline $\begin{array}{l}\text { MD1.0- } \\
\text { A90 }\end{array}$ & 0.3 & 1.9 & 21.9 & 1.4 & 114.9 & 0.8 & 166.3 & 5.0 & 9.4 & GFRP & Type I \\
\hline $\begin{array}{c}\text { G1.0- } \\
\text { T0.7-A90 }\end{array}$ & 1.6 & 3.9 & 6.3 & 1.1 & 160.7 & 1.2 & 237.3 & 3.6 & 4.4 & GFRP & Type I \\
\hline $\begin{array}{c}\text { G0.6- } \\
\text { T1.0-A90 }\end{array}$ & 0.6 & 4.2 & 17.1 & 1.3 & 195.4 & 1.1 & 250.1 & 3.8 & 4.3 & GFRP & Type I \\
\hline \multicolumn{12}{|c|}{ Yinghao \& Yong [5] } \\
\hline S2 & 0.3 & 2.6 & 19.9 & 1.4 & 66.7 & 1.6 & 93.1 & 5.5 & 4.7 & GFRP & Type II \\
\hline S3 & 0.3 & 3.8 & 29.9 & 1.6 & 72.8 & 1.4 & 95.2 & 5.8 & 5.5 & GFRP & Type II \\
\hline S4 & 0.3 & 1.7 & 24.6 & 1.6 & 75.0 & 1.3 & 103.2 & 5.5 & 5.7 & GFRP & Type I \\
\hline \multicolumn{12}{|c|}{ Refai et al. [8] } \\
\hline $\begin{array}{c}2 \mathrm{G} 12- \\
1 \mathrm{~S} 10\end{array}$ & 2.9 & 5.3 & 0.7 & 1.1 & 15.2 & 1.4 & 47.3 & 8.2 & 18.5 & GFRP & Type I \\
\hline
\end{tabular}




\begin{tabular}{|c|c|c|c|c|c|c|c|c|c|c|c|}
\hline $\begin{array}{c}\text { 2G12- } \\
2 \mathrm{~S} 10\end{array}$ & 1.4 & 3.0 & 3.2 & 1.1 & 25.9 & 1.3 & 58.4 & 7.1 & 12.3 & GFRP & Type I \\
\hline $\begin{array}{c}2 \mathrm{G} 12- \\
2 \mathrm{~S} 12\end{array}$ & 1.0 & 4.4 & 5.5 & 1.1 & 31.1 & 1.5 & 55.7 & 6.8 & 8.2 & GFRP & Type I \\
\hline $\begin{array}{c}2 \mathrm{G} 16- \\
2 \mathrm{~S} 10\end{array}$ & 2.6 & 3.8 & 1.3 & 1.0 & 31.0 & 1.4 & 71.4 & 5.8 & 9.8 & GFRP & Type I \\
\hline $\begin{array}{l}\text { 2G16- } \\
2 \mathrm{~S} 12\end{array}$ & 1.8 & 2.4 & 2.6 & 1.1 & 37.4 & 1.4 & 70.9 & 5.5 & 7.3 & GFRP & Type I \\
\hline $\begin{array}{r}2 \mathrm{G} 16- \\
2 \mathrm{~S} 16\end{array}$ & 1.0 & 4.0 & 7.1 & 1.1 & 56.5 & 1.6 & 81.4 & 4.7 & 4.4 & GFRP & Type I \\
\hline
\end{tabular}

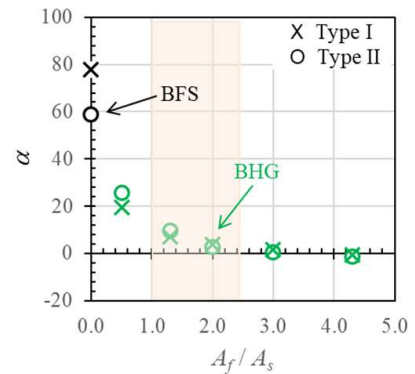

(a)

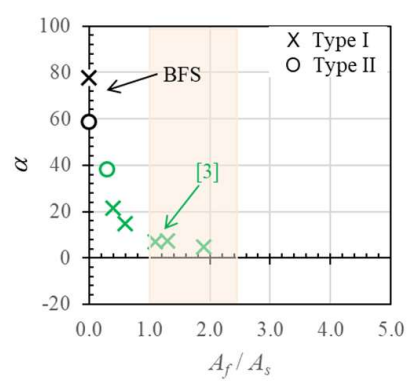

(d)

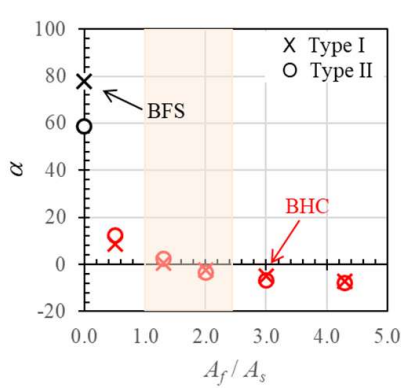

(b)

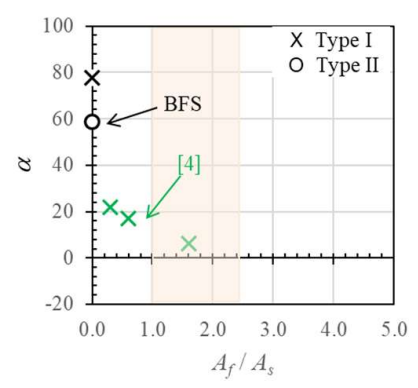

(e)

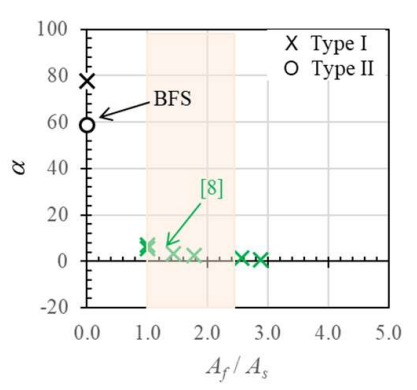

(g)

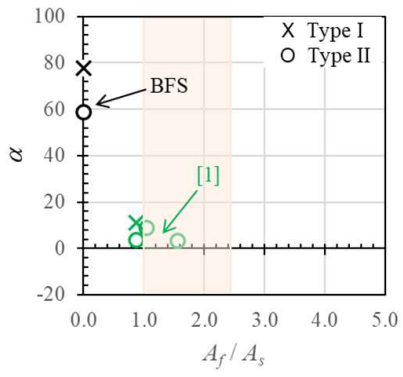

(c)

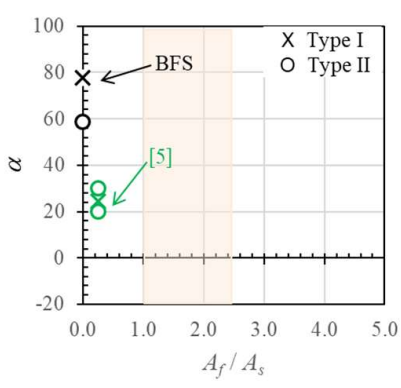

(f)

Figure 16. Neutral axis angle $(\alpha)$ versus hybrid reinforcement ratio $\left(A_{f} / A_{s}\right)$ of the tested beams, parametric study, and data obtained from the literature. 


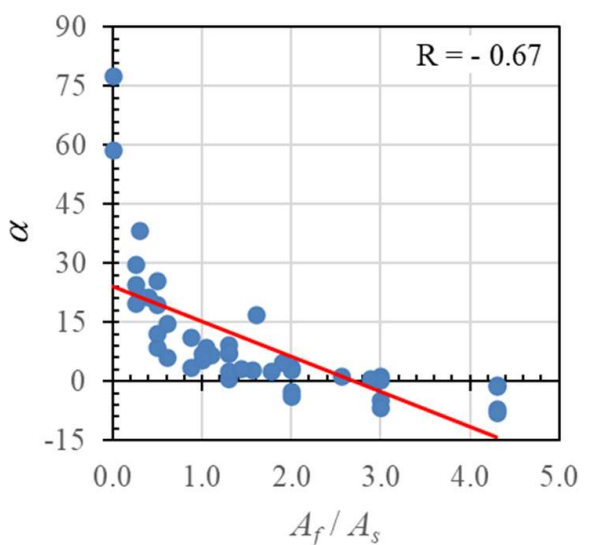

(a)

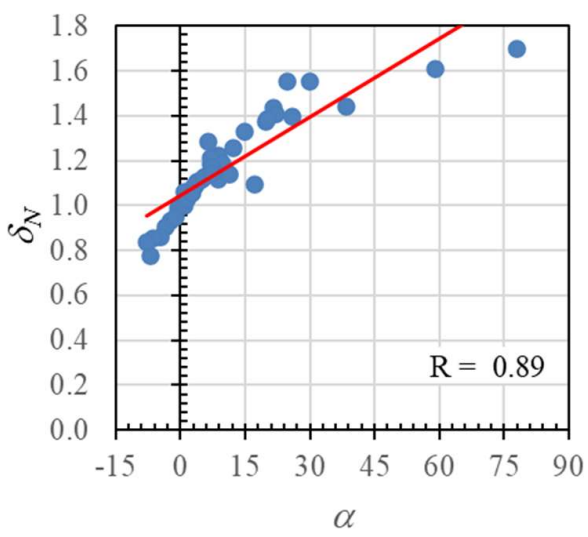

(c)

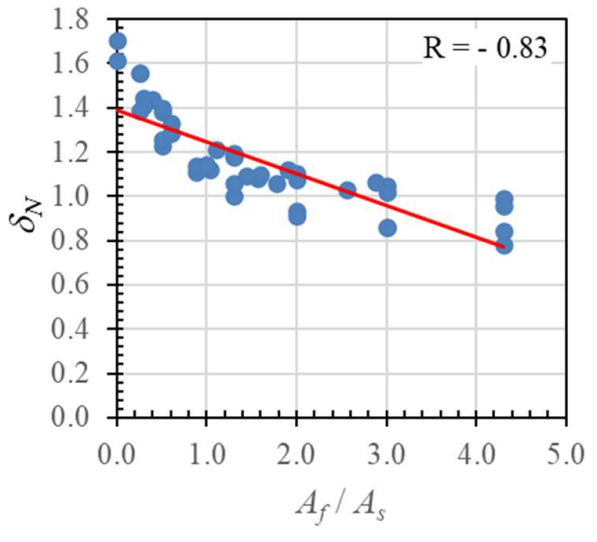

(b)

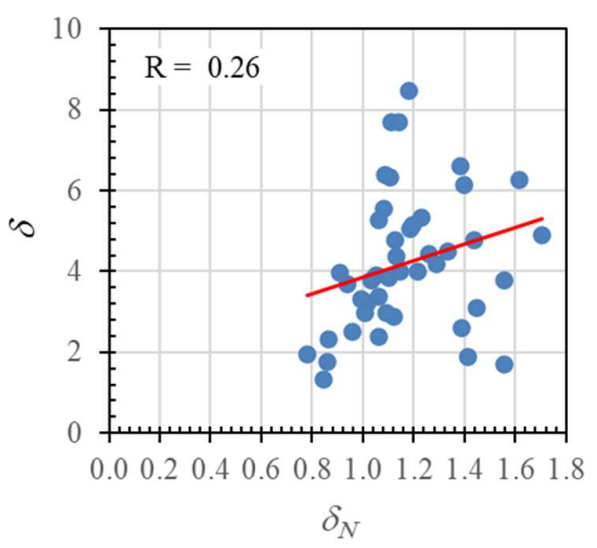

(d)

Figure 17. Relationship between (a) hybrid reinforcement ratio and neutral axis angle, (b) hybrid reinforcement ratio and neutral axis displacement index, (c) neutral axis angle and neutral axis displacement index, and (d) neutral axis displacement index and ductility of the tested beams, parametric study, and data obtained from the literature.

Refai et al. [8] proposed the use of a modified deformation factor, a measure of the ability of a beam to sustain inelastic deformation and significant rotation before failure. This is the ratio of the product of the moment and curvature at ultimate yielding to the product of the moment and curvature at the yielding of the steel reinforcement as shown in Figure 18 and given in Equation (9). The calculated deformation factors for all data in this study are shown in Table 3. 


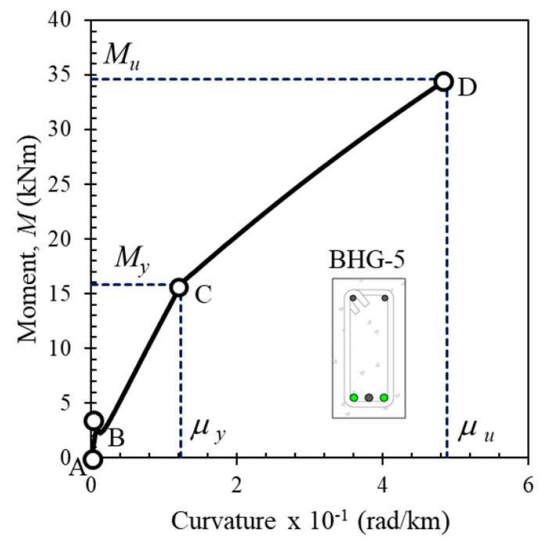

Figure 18. The moment-curvature curve obtained from cross-section analysis (fiber element model).

$$
D F_{\text {mod }}=\frac{M_{u} \mu_{u}}{M_{y} \mu_{y}}
$$

The relationship between the deformation factor $(D F)$ and the reinforcement ratio $\left(A_{f} / A_{s}\right)$, the neutral axis angle $(\alpha)$, neutral axis displacement index $\left(\delta_{\mathrm{N}}\right)$, and ductility $(\delta)$ is shown in Figure 19 with the correlation values of $-0.1,-0.06,0.06$, and 0.58 respectively.

The trend line in Figure 19(a) and (b) show a decrease of the deformation factor with an increase in the reinforcement ratio and neutral axis angle. Meanwhile, Figure 19(c) and (d) show an increase in the deformation factor with the increase in neutral axis displacement index ductility. Figure 19(d) indicates the significant correlation between the deformation factor and the ductility.

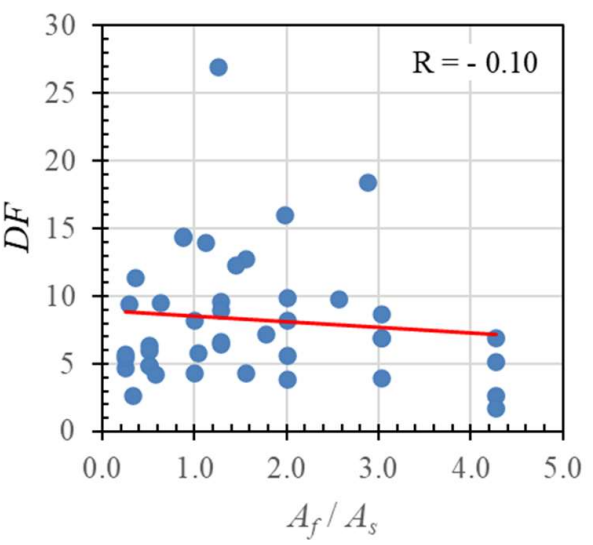

(a)

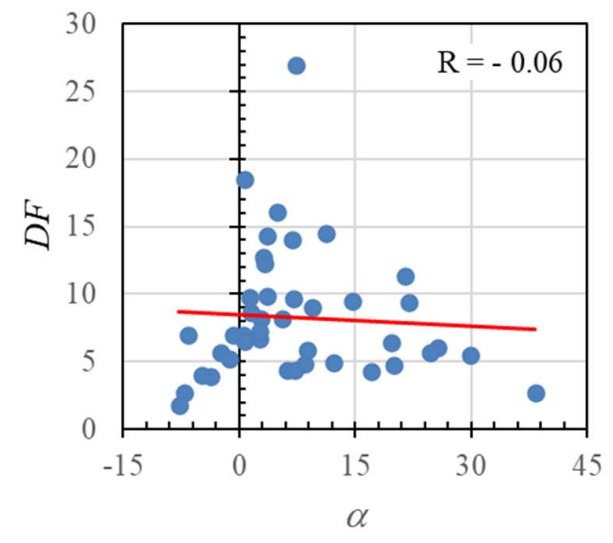

(b) 


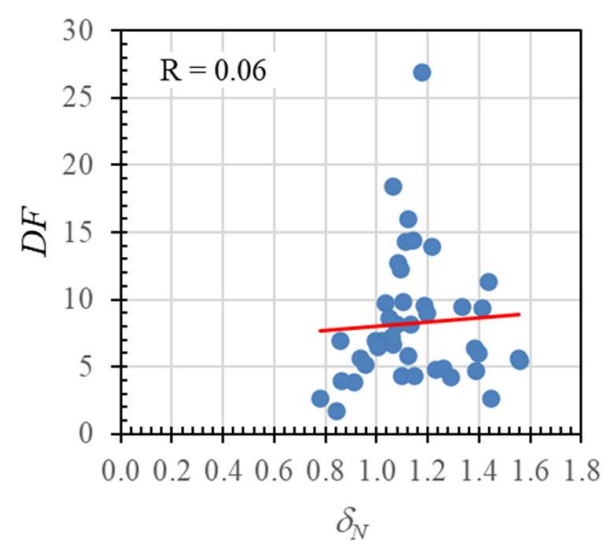

(c)

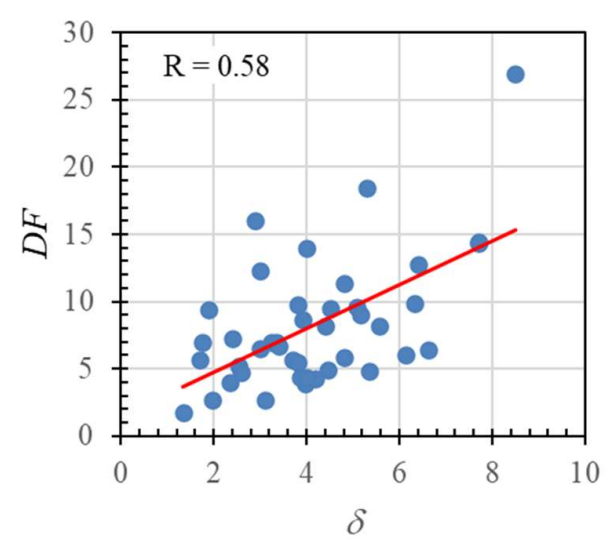

(d)

Figure 19. Relationship between (a) hybrid reinforcement ratio and deformability factor, (b) neutral axis angle and deformability factor, (c) neutral axis deformation index and deformability factor, and (d) ductility and deformability factor of the tested beams, parametric study, and data obtained from the literature.

The explanation above shows some weak correlation values between the two variables being compared. The above analysis uses data from the literature that uses varied material types (e.g., modulus of elasticity and tensile strength of FRP and steel, concrete quality, cross-sectional size, beam dimensions). Therefore, in Figure 20, only the results processed using parametric study data are presented. In this parametric study, only the hybrid reinforcement ratio variable is varied, as shown in Table 1 above.

It can be seen from these figures that the correlation values obtained are a strong relationship (greater than 0.65). With the results presented in Figure 20, we can determine the recommended values of parameters $\alpha, \delta \mathrm{N}, \delta$, and $D F$ for cross-section with hybrid reinforcement. The dotted circle indicates the range of recommended values in Figure 20.

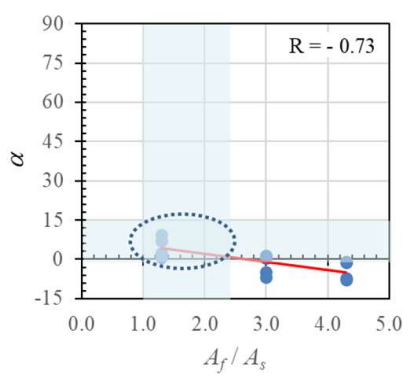

(a)

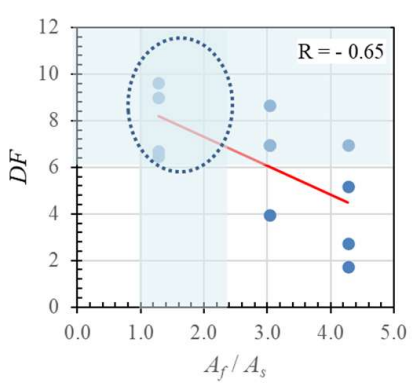

(d)

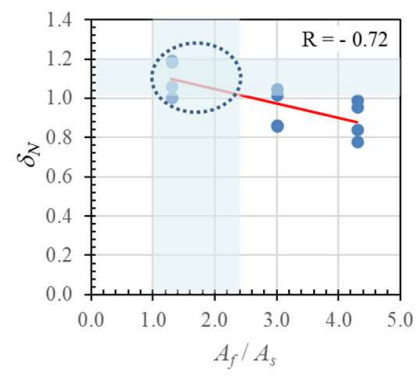

(b)

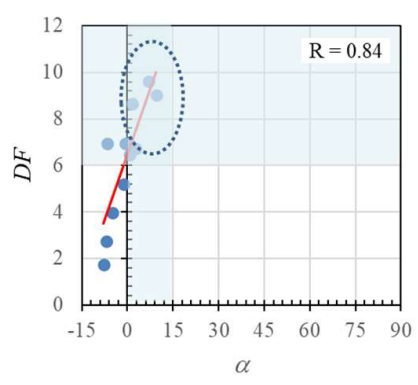

(e)

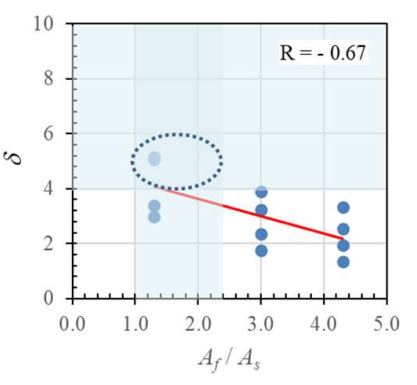

(c)

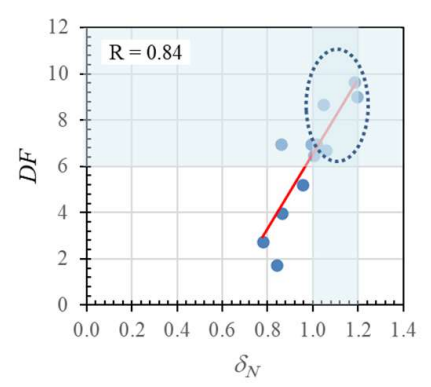

(f) 
Figure 20. Relationship between $\alpha, \delta \mathrm{N}, \delta$, and $D F$ for cross-section with hybrid reinforcement obtained from the parametric study.

The process of determining the recommended values of the parameter begins by using the suggested limitation value for the hybrid reinforcement ratio [9], which is the range between 1 - 2.5, as shown in Figure 20(a). A zone of a value that meets the requirements is obtained from the limit of the hybrid reinforcement ratio, which is between 0 $15^{0}$. This process is repeated to obtain the boundary zone of the other parameters (dotted circle). A summary of the recommended values is listed in Table 4.

Table 4. Recommended parameter values of $\alpha, \delta \mathrm{N}, \delta$, and $D F$ for cross-section with hybrid reinforcement.

\begin{tabular}{cc}
\hline Parameter & Recommended Value \\
\hline$\alpha$ & $0-15^{0}$ \\
$\delta \mathrm{N}$ & $1-1.2$ \\
$\delta$ & $>4$ \\
$\mathrm{DF}$ & $>6$ \\
\hline
\end{tabular}

\section{Conclusions}

Fourteen reinforced concrete beams together with data from parametric study and data obtained from literature with various hybrid reinforcement ratios and reinforcement positions were tested to evaluate the ductility of the beams. Some conclusions that can be drawn from this study are:

(1) The reinforcement ratio $\left(A_{f} / A_{s}\right)$ strongly influences hybrid reinforced concrete's capacity and cross-sectional ductility. The higher the ratio of hybrid reinforcement, the greater the capacity but the reduced ductility. The ductility of beams decreases with the increase of the hybrid reinforcement ratio.

(2) In an under-reinforced cross-section (steel reinforcement), the neutral axis curve can be divided into three zones. While in a beam with an over-reinforced cross-section, there are only two-zone. In under or over-reinforced cross-section (FRP reinforcement), the neutral axis curve can be divided two zones.

(3) There are three zones on the neutral axis curve for beams cross-section with hybrid reinforcement, i.e., the zone before cracking, the zone after cracking, and the zone after yielding. The inclination angle of the neutral axis curve after reinforcement yield depends on the type of FRP used and the hybrid reinforcement ratio.

(4) The ductility of beams with hybrid reinforcement increases as the neutral axis angle increases. There is a significant relationship between the neutral axis angle, neutral axis deformation index, the deformation factor, and ductility. The deformation factor increases with increasing neutral axis angle and neutral axis deformation index.

(5) The neutral axis angle and the neutral axis deformation index proposed in this paper can be used to evaluate the ductility value of the cross-section with hybrid reinforcement.

Acknowledgments: This research was funded by the Department of Civil Engineering, Faculty of Engineering, Andalas University, with 12/UN16.09.3/PP/2021.

\section{References}

[1] Aiello, M.A.; Ombres, L. Structural performances of concrete beams with hybrid (Fiber-reinforced polymer-steel) reinforcements. J. Compos. Constr. 2002, 6, 133-140.

[2] Nadjai, A.; Talamona, D.; Ali, F. Fire Performance of Concrete Beams Reinforced with FRP Bars. Proc. of Int. Symp. on Bond Behaviour of FRP in Structures, Hongkong. 2005, 401-410. 
[3] Qu, W.; Zhang, X.; Huang, H. Flexural behavior of concrete beams reinforced with hybrid (GFRP and steel) bars. J. Compos. Constr. 2009, 13, 350-359.

[4] Lau, D.; Pam, H.J. Experimental study of hybrid FRP reinforced concrete beams. Eng. Struct. 2010, 32, $3857-3865$.

[5] Yinghao, L.; Yong, Y. Arrangement of hybrid rebars on flexural behavior of HSC beams. Compos. Part B 2013, 45, $22-31$.

[6] Ge, W.; Zhang, J.; Cao, D.; Tu, Y. Flexural behaviors of hybrid concrete beams reinforced with BFRP bars and steel bars. Constr. Build. Mater. 2015, 87, 28-37.

[7] Kara, L.F.; Ashour, A.F.; Köroglu, M.A. Flexural behavior of hybrid FRP/steel reinforced concrete beams. Compos. Struct. 2015, $129,111-121$.

[8] El Refai, A.; Abed, F.; Al-Rahmani, A. Structural performance and serviceability of concrete beams reinforced with hybrid (GFRP and steel) bars. Constr. Build. Mater. 2015, 96, 518-529.

[9] Qin, R.; Zhou, A.; Lau, D. Effect of reinforcement ratio on the flexural performance of hybrid FRP reinforced concrete beams. Composites Part B. 2017, 108, 200-209.

[10] Bui, L.V.H.; Stitmannaithum, B.; Ueda, T. Ductility of Concrete Beams Reinforced with Both Fiber-Reinforced Polymer and Steel Tension Bars. Journal of Advanced Concrete Technology. 2018, 16, 531-548.

[11] Araba, A.M.; Ashour, A. F.; Flexural performance of hybrid GFRP-Steel reinforced concrete continuous beams. Composites Part B. 2018, 154, 321-336.

[12] Sun, Z.; Fu, L.; Feng, D.C.; Vatuloka, A.R.; Wei, Y.; Wu, G. Experimental study on the flexural behavior of concrete beams reinforced with bundled hybrid steel/FRP bars. Engineering Structures 2019, 197, 109443.

[13] Kartal, S.; Kalkan, I.; Beycioglu, A.; Dobiszewska, M. Load-Deflection Behavior of Over and Under-Reinforced Concrete Beams with Hybrid FRP-Steel Reinforcements. Materials 2021, 14, 5341.

[14] Park, R.; Paulay, T. Reinforced Concrete Structures; Wiley: New York, NY, USA, 1975; p. 769.

[15] Mander, J.B.; Priestley, M.J.N.; Park, R. Theoretical Stress-Strain Model for Confined Concrete. J. Struct. Eng. 1988, 114, 18041826.

[16] Thamrin, R.; Sari, R.P. Flexural Capacity of Strengthened Reinforced Concrete Beams with Web Bonded Steel Plates. Procedia Eng. 2017, 171, 1129-1136.

[17] Thamrin, R. Effect of Strengthening Method and Anchorage Length on Flexural Capacity of RC Beams with Steel Plates. J. Eng. Sci. Technol. 2018, 13, 3781-3794.

[18] Thamrin, R. Analytical Prediction on Flexural Response of RC Beams Strengthened with Steel Plates. In Proceedings of the MATEC Web of Conferences: International Symposium on Civil and Environmental Engineering (ISCEE), $2017,103,02012$.

[19] Thamrin, R.; Zaidir, Z.; Desharma, S. Debonding Failure Analysis of Reinforced Concrete Beams Strengthened with CFRP Plates. Polymers 2021, 13, 2738.

[20] Bernardo, L.F.A.; Lopes, S.M.R. Neutral axis depth versus flexural ductility in high strength concrete beams. J. Struct. Eng.2004,130, 452-459.

[21] Bentz, E.; Collins, M.P. Response 2000, Version 1.0.5; University of Toronto: Toronto, ON, Canada, 2001. 